\title{
Discrimination of Head and Neck Squamous Cell Carcinoma Patients and Healthy Adults by 10-Color Flow Cytometry: Development of a Score Based on Leukocyte Subsets
}

\author{
Gunnar Wichmann ${ }^{1,2, *, \dagger}$, Clara Gaede ${ }^{1, \dagger}$, Susanne Melzer ${ }^{2,3}$, Jozsef Bocsi ${ }^{2}$, Sylvia Henger ${ }^{2,4}$, \\ Christoph Engel 2,4 ${ }^{(D}$, Kerstin Wirkner ${ }^{2}$, John Ross Wenning ${ }^{1}$, Theresa Wald ${ }^{1}$, Josefine Freitag ${ }^{1}$, \\ Maria Willner ${ }^{1}$, Marlen Kolb ${ }^{1}$, Susanne Wiegand ${ }^{1}$, Markus Löffler ${ }^{2,4}$, Andreas Dietz ${ }^{1,2, \ddagger}$ \\ and Attila Tárnok $2,5,6, \ddagger$ \\ 1 Clinic for Otorhinolaryngology, Head and Neck Surgery, University Hospital Leipzig, Liebigstr. 10-14, \\ 04103 Leipzig, Germany; clara.gaede@googlemail.com (C.G.); j.wenning@gmx.net (J.R.W.); \\ wald.theresa@web.de (T.W.); Josefine.Freitag@web.de (J.F.); maria.willner93@gmail.com (M.W.); \\ marlen.kolb@medizin.uni-leipzig.de (M.K.); Susanne.Wiegand@medizin.uni-leipzig.de (S.W.); \\ Andreas.Dietz@medizin.uni-leipzig.de (A.D.) \\ 2 LIFE-Leipzig Research Center for Civilization Diseases, University of Leipzig, Philipp-Rosenthal-Str. 27, \\ 04103 Leipzig, Germany; susanne.melzer@zks.uni-leipzig.de (S.M.); jozsef.bocsi@gmx.de (J.B.); \\ sylvia.henger@imise.uni-leipzig.de (S.H.); christoph.engel@imise.uni-leipzig.de (C.E.); \\ Kerstin.Wirkner@medizin.uni-leipzig.de (K.W.); markus.loeffler@imise.uni-leipzig.de (M.L.); \\ atarnok@hotmail.com (A.T.) \\ 3 Clinical Trial Centre Leipzig, University Leipzig, Härtelstr. 16-18, 04107 Leipzig, Germany \\ 4 Institute for Medical Informatics, Statistics and Epidemiology (IMISE), University of Leipzig, Härtelstr. \\ 10-18, 04107 Leipzig, Germany \\ 5 Department of Precision Instruments, Tsinghua University, Beijing 100084, China \\ 6 Fraunhofer Institute for Cell Therapy and Immunology IZI, Perlickstr. 1, 04103 Leipzig, Germany \\ * Correspondence: gunnar.wichmann@medizin.uni-leipzig.de; Tel.: +49-341-9721926; Fax: +49-341-9721909 \\ + These authors share equal contribution. \\ $\ddagger$ These authors share equal senior authorship.
}

Received: 22 March 2019; Accepted: 10 June 2019; Published: 12 June 2019

check for updates

\begin{abstract}
Background: Leukocytes in peripheral blood (PB) are prognostic biomarkers in head and neck squamous cell carcinoma cancer patients (HNSCC-CPs), but differences between HNSCC-CPs and healthy adults (HAs) are insufficiently described. Methods: 10-color flow cytometry (FCM) was used for in-depth immunophenotyping of PB samples of 963 HAs and 101 therapy-naïve HNSCC-CPs. Absolute (AbsCC) and relative cell counts (RelCC) of leukocyte subsets were determined. A training cohort (TC) of 43 HNSCC-CPs and 43 HAs, propensity score (PS)-matched according to age, sex, alcohol, and smoking, was used to develop a score consecutively approved in a validation cohort (VC). Results: Differences in AbsCC were detected in leukocyte subsets $(p<0.001)$, but had low power in discriminating HNSCC-CPs and HAs. Consequently, RelCC of nine leukocyte subsets in the TC were used to calculate 36 ratios; receiver operating characteristic (ROC) curves defined optimum cut-off values. Binary classified data were combined in a score based on four ratios: monocytes-to-granulocytes (MGR), classical monocytes-to-monocytes (clMMR), monocytes-to-lymphocytes (MLR), and monocytes-to-T-lymphocytes (MTLR); $\geq 3$ points accurately discriminate HNSCC-CPs and HAs in the PS-matched TC $\left(p=2.97 \times 10^{-17}\right)$, the VC $\left(p=4.404 \times 10^{-178}\right)$, and both combined $\left(p=7.74 \times 10^{-199}\right)$. Conclusions: RelCC of leukocyte subsets in PB of HNSCC-CPs differ significantly from those of HAs. A score based on MGR, clMMR, MLR, and MTLR allows for accurate discrimination.
\end{abstract}


Keywords: head and neck squamous cell carcinoma (HNSCC); multicolor flow cytometry; peripheral blood; leukocyte subsets; cancer biomarker; predictive value; monocytes-to-lymphocytes ratio (MLR); monocytes-to-granulocytes ratio (MGR); classical monocytes; propensity score matching

\section{Introduction}

Head and neck squamous cell carcinoma (HNSCC) is the sixth most common malignant tumor in the world [1,2]. The development of HNSCC is strongly associated with tobacco and high-level alcohol consumption as well as infection with high-risk subtypes of the human papillomavirus (HPV). Particular human leukocyte antigen (HLA) alleles and haplotypes have been linked to the development of HNSCC and prognosis independent of these risk factors [3,4]. Several studies investigated the absolute (AbsCC) and relative cell count (RelCC) and the change in leukocyte subsets that occurred in association with the disease. As these subsets are known to play a key role in immune surveillance and anti-tumor immune responses, which are dependent on the effective cooperation of monocyte-derived antigen-presenting cells (APC) in the stimulation of cytotoxic (Tc, $\mathrm{CD}^{+} \mathrm{CD}^{+}$) and helper T-cells (Th, $\mathrm{CD}^{+} \mathrm{CD}^{+}$), $\mathrm{AbsCC}$ and RelCC of these leukocytes are thought to be critical in the development of HNSCC. For example, a low level of invariant natural killer T cells (iNKT) is associated with a poor outcome [5]. Regulatory T-cells (Treg, $\mathrm{CD}^{+} \mathrm{CD}^{+} \mathrm{CD} 25^{+}$) mediate immune suppression by secreting interleukin (IL-) 10 and transforming growth factor (TGF-) $\beta$ to provide a helpful tolerogenic environment for tumor development and progression [6,7]. Absolute numbers of neutrophils, lymphocytes, and monocytes are higher in HNSCC and venous blood [6-8]; high numbers of neutrophils indicate a poor prognosis in several cancers, including HNSCC, because of their tumor-promoting activities, such as migration, angiogenesis, invasion, metastasis, immunosuppression, and mutagenesis [8-10]. A recent study showed the frequency of $\mathrm{CD} 14^{+} \mathrm{CD} 16^{-} \mathrm{HLA}-\mathrm{DR} \mathrm{R}^{\text {high }}$ monocytes to be a strong predictor of progression-free (PFS) as well as overall survival (OS) in response to anti-PD-1 immunotherapy with the immune-checkpoint inhibitor; a clear response to the treatment was also shown in the T-cell compartment [11]. Ratios of various leukocyte subsets have been shown to be strong survival predictors in HNSCC. A high lymphocyte-to-monocyte ratio (LMR) or, vice versa, a low monocyte-to-lymphocyte (MLR) ratio in peripheral blood, were proven to be associated with a good prognosis in several HNSCC studies [12,13], whereas a high neutrophil-to-lymphocyte (NLR) ratio, as well as a high platelet-to-lymphocyte (PLR) ratio, corresponded with decreased disease-free survival (DFS) and OS [13,14].

Whereas the majority of these studies aimed at linking changes in leukocyte subsets to the stage of the disease (early vs. advanced, with or without loco-regional or distant metastasis), localization of the primary lesion as well as the $\mathrm{T}, \mathrm{N}$, and $\mathrm{M}$ categories, our aim was to detect how subsets of leukocytes in blood samples of HNSCC-cancer patients (HNSCC-CPs) differ from those taken from healthy adults (HAs). Moreover, we aimed to elucidate if differences may allow for discriminating HNSCC-CPs and HAs, potentially by building a score that summarizes these differences.

We hypothesized that high-throughput measurement utilizing 10-color flow cytometry (FCM) and parallel enumeration of leukocyte subsets in a large population-based HA cohort and a cohort of HNSCC-CPs would allow for reliable quantification of leukocyte subsets and calculation of MLR, NLR, and other ratios to discriminate HNSCC-CPs from HAs. Earlier studies suffer from potential contamination of leukocyte subsets caused by the earlier unavoidable technical limitations. These limitations resulted from low throughput and the use of two or three fluorescence-detection channels only. This led to small numbers of simultaneously analyzable staining patterns and, hence, a low number of enumerable leukocyte subsets in a single run. Unfortunately, this caused the error-prone need to combine multiple runs to do the immunophenotyping. Benefitting from advances in flow cytometry, especially high-throughput measurement utilizing 10-color FCM and parallel enumeration of leukocyte subsets by use of an optimized multicolor immunofluorescence panel (OMIP) 
consisting of 13 monoclonal antibodies to overcome the discussed limitations (OMIP-023 [15]), we were able to analyze a total of 15 leukocyte subsets simultaneously. Based on these high-quality data, we are able to show differences between HNSCC-CPs and HAs and present a leukocyte score that focuses on the most significant altered ratios in HNSCC-CPs able to discriminate both.

\section{Results}

The CONSORT diagram (Figure 1) shows information about selection of patients.

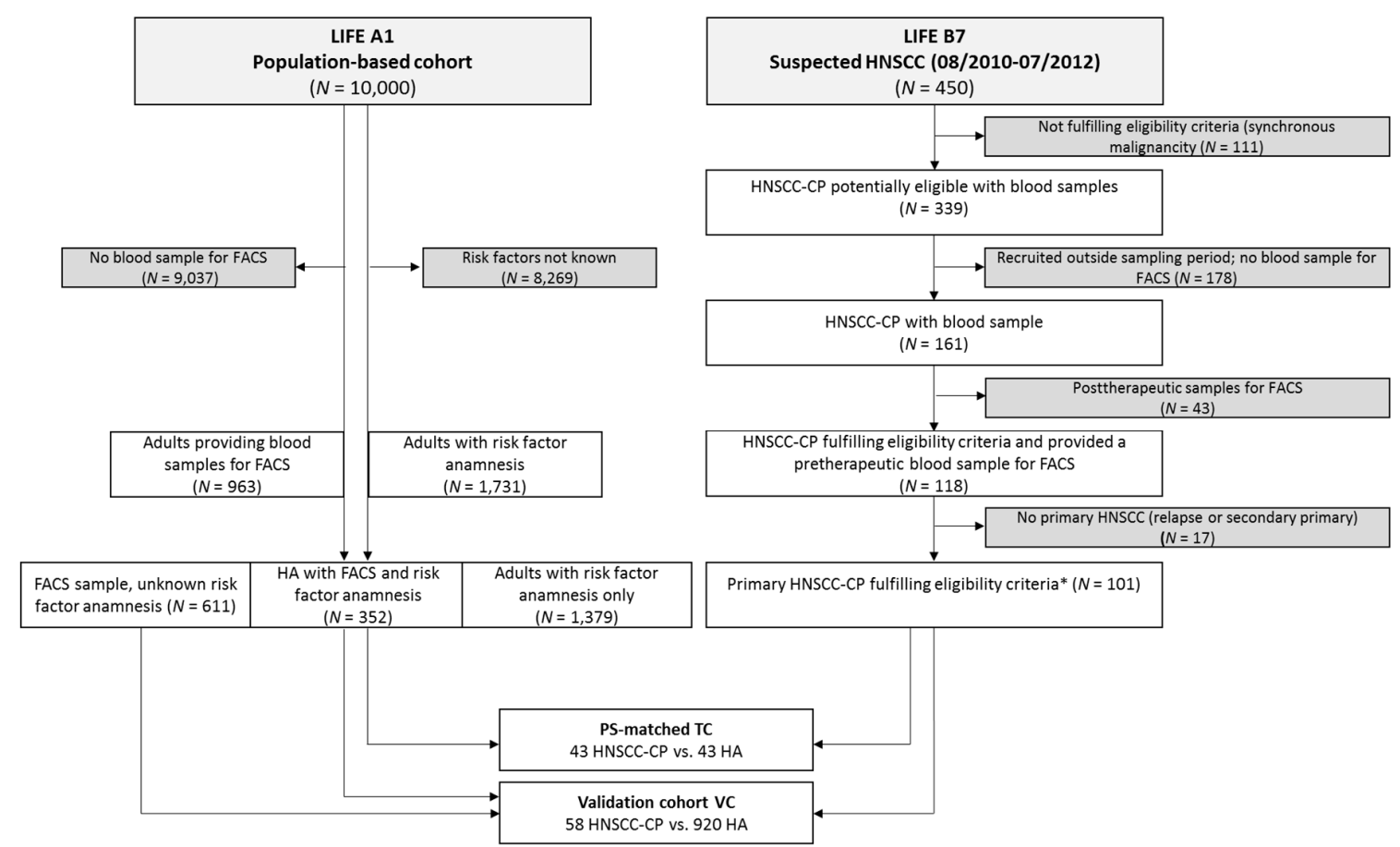

Figure 1. The CONSORT diagram. The selection of healthy adults (HAs, left) and head and neck squamous cell carcinoma cancer patients (HNSCC-CPs, right) are shown together with excluded samples by reason. Details regarding propensity score (PS)-matching to define the training cohort (TC) and the validation cohort (VC) can be found in the Methods section.

Eligible for final analysis were 101 HNSCC-CPs as well as 963 HAs. First, the AbsCCs of the different leukocyte subsets of HNSCC-CPs and HAs were compared (Table 1). 
Table 1. The mean and $95 \%$ confidence intervals (CI) for absolute cell counts (AbsCC) in $10^{9} \cdot \mathrm{L}^{-1}$ of leukocyte subsets in peripheral blood detected by 10-color flow cytometry utilizing the optimized multicolor immunofluorescence panel (OMIP)-023 [15] in healthy adults (HAs) and HNSCC cancer patients (HNSCC-CPs) in the propensity-score-matched training cohort (TC), the validation cohort (VC), and both combined. Significant differences are shown in bold.

\begin{tabular}{|c|c|c|c|c|c|c|}
\hline Leukocyte Subsets & Marker & \multicolumn{2}{|c|}{$\begin{array}{l}\text { Healthy Adults (HAs) } \\
\text { Mean }(95 \% \text { CI) }\end{array}$} & \multicolumn{2}{|c|}{$\begin{array}{c}\text { HNSCC Patients } \\
\text { (HNSCC-CPs) } \\
(95 \% \mathrm{CI})\end{array}$} & $p$-Value * \\
\hline Combined $^{\mathrm{a}}$ & $n$ & \multicolumn{2}{|c|}{935} & \multicolumn{2}{|c|}{101} & \\
\hline Granulocytes & SSChigh & 3.93 & $(3.84-4.02)$ & 4.81 & $(4.41-5.22)$ & 0.0001 \\
\hline Neutrophils & $\mathrm{SSC}^{\text {high }} \mathrm{CD} 16^{+}$ & 3.64 & $(3.55-3.73)$ & 4.67 & $(4.27-5.07)$ & $<0.0001$ \\
\hline Eosinophils & $\mathrm{SSC}^{\text {high }} \mathrm{CD} 16^{-}$ & 0.14 & $(0.13-0.15)$ & 0.14 & $(0.12-0.16)$ & 0.8979 \\
\hline classical m. & $\mathrm{SSC}^{\text {med }} \mathrm{CD} 14^{\text {high }} \mathrm{CD} 16^{\text {dim }}$ & 0.22 & $(0.21-0.23)$ & 0.32 & $(0.29-0.35)$ & $<0.0001$ \\
\hline Lymphocytes & SSC $^{\text {low }}$ & 1.77 & $(1.73-1.81)$ & 1.01 & $(0.91-1.10)$ & $<0.0001$ \\
\hline B-cells & $\mathrm{CD}^{-}{ }^{-} \mathrm{CD} 16 / \mathrm{CD} 6^{-} \mathrm{CD} 9^{+}$ & 0.19 & $(0.18-0.20)$ & 0.17 & $(0.15-0.20)$ & 0.2814 \\
\hline T-cells & $\mathrm{CD}^{+} \mathrm{CD} 16 / \mathrm{CD}^{-} 6^{-}$ & 1.23 & $(1.20-1.26)$ & 0.91 & $(0.82-0.99)$ & $<0.0001$ \\
\hline Tc cells & $\mathrm{CD}^{+} \mathrm{CD}^{+}$ & 0.24 & $(0.23-0.26)$ & 0.19 & $(0.16-0.22)$ & 0.0011 \\
\hline DPT & $\mathrm{CD}^{+} \mathrm{CD}^{+}{ }^{+} \mathrm{CD} 8^{+}$ & 0.02 & $(0.02-0.02)$ & 0.01 & $(0.01-0.02)$ & $<0.0001$ \\
\hline PS-matched TC ${ }^{b}$ & $n$ & \multicolumn{2}{|c|}{43} & \multicolumn{2}{|c|}{43} & \\
\hline Granulocytes & SSC high & 3.84 & $(3.41-4.28)$ & 4.69 & $(4.05-5.32)$ & 0.0370 \\
\hline Neutrophils & $\mathrm{SSC}^{\text {high }} \mathrm{CD} 16^{+}$ & 3.66 & $(3.24-4.08)$ & 4.56 & $(3.94-5.19)$ & 0.0234 \\
\hline Eosinophils & $\mathrm{SSC}^{\text {high }} \mathrm{CD} 16^{-}$ & 0.17 & $(0.12-0.21)$ & 0.12 & $(0.09-0.16)$ & 0.1334 \\
\hline Monocytes & $\mathrm{SSC}^{\text {med }} \mathrm{CD} 14^{\text {high }}$ & 0.31 & $(0.28-0.34)$ & 0.37 & $(0.31-0.42)$ & 0.0838 \\
\hline nonclassical m. & $\mathrm{SSC}{ }^{\text {med }} \mathrm{CD} 14^{\text {dim }} \mathrm{CD} 16^{\text {high }}$ & 0.03 & $(0.03-0.04)$ & 0.04 & $(0.03-0.05)$ & 0.3462 \\
\hline classical m. & $\mathrm{SSC}^{\text {med }} \mathrm{CD} 14^{\text {high }} \mathrm{CD}^{\mathrm{dim}}$ & 0.27 & $(0.24-0.30)$ & 0.32 & $(0.27-0.37)$ & 0.1235 \\
\hline Lymphocytes & SSC $^{\text {low }}$ & 1.84 & $(1.66-2.02)$ & 1.02 & $(0.89-1.15)$ & $<0.0001$ \\
\hline B-cells & $\mathrm{CD}^{-}{ }^{-\mathrm{CD}} 16 / \mathrm{CD} 6^{-} \mathrm{CD}^{-} 9^{+}$ & 0.21 & $(0.17-0.24)$ & 0.17 & $(0.14-0.20)$ & 0.0979 \\
\hline T-cells & $\mathrm{CD}^{+} \mathrm{CD} 16 / \mathrm{CD}^{2} 6^{-}$ & 1.20 & $(1.08-1.33)$ & 0.91 & $(0.79-1.03)$ & 0.0015 \\
\hline Tc cells & $\mathrm{CD}^{+} \mathrm{CD}^{+}$ & 0.20 & $(0.17-0.24)$ & 0.20 & $(0.15-0.25)$ & 0.9290 \\
\hline Neutrophils & $\mathrm{SSC}^{\text {high }} \mathrm{CD} 16^{+}$ & 3.64 & $(3.55-3.73)$ & 4.75 & $(4.23-5.27)$ & 0.0001 \\
\hline Eosinophils & $\mathrm{SSC}^{\text {high }} \mathrm{CD} 16^{-}$ & 0.14 & $(0.13-0.15)$ & 0.15 & $(0.13-0.18)$ & 0.2848 \\
\hline Monocytes & $\mathrm{SSC}^{\text {med }} \mathrm{CD} 14^{\text {high }}$ & 0.26 & $(0.25-0.26)$ & 0.36 & $(0.32-0.40)$ & $<0.0001$ \\
\hline nonclassical m. & $\mathrm{SSC}{ }^{\mathrm{med}} \mathrm{CD} 14^{\mathrm{dim}} \mathrm{CD} 16^{\text {high }}$ & 0.03 & $(0.03-0.04)$ & 0.04 & $(0.03-0.04)$ & 0.5644 \\
\hline classical m. & $\mathrm{SSC}^{\mathrm{med}} \mathrm{CD} 14^{\mathrm{high}} \mathrm{CD} 16^{\mathrm{dim}}$ & 0.22 & $(0.21-0.22)$ & 0.32 & $(0.28-0.36)$ & $<0.0001$ \\
\hline Lymphocytes & SSC $^{\text {low }}$ & 1.76 & $(1.72-1.81)$ & 1.00 & $(0.87-1.13)$ & $<0.0001$ \\
\hline B-cells & 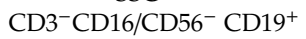 & 0.19 & $(0.17-0.20)$ & 0.18 & $(0.15-0.21)$ & 0.4031 \\
\hline T-cells & $\mathrm{CD}^{+}{ }^{\mathrm{CD}} 16 / \mathrm{CD} 6^{-}$ & 1.23 & $(1.20-1.27)$ & 0.91 & $(0.79-1.03)$ & $<0.0001$ \\
\hline Tc cells & $\mathrm{CD}^{+} \mathrm{CD}^{+}$ & 0.25 & $(0.23-0.26)$ & 0.18 & $(0.14-0.21)$ & 0.0011 \\
\hline DPT & $\mathrm{CD}^{+} \mathrm{CD}^{+}{ }^{+} \mathrm{CD} 8^{+}$ & 0.02 & $(0.02-0.02)$ & 0.01 & $(0.01-0.01)$ & $<0.0001$ \\
\hline Th cells & $\mathrm{CD}^{+} \mathrm{CD}^{+}{ }^{+}$ & 0.89 & $(0.86-0.91)$ & 0.76 & $(0.65-0.86)$ & 0.0221 \\
\hline regulatory T-cells e & $\mathrm{CD}^{+}{ }^{+} \mathrm{CD} 4^{+} \mathrm{CD}_{25}{ }^{+} \mathrm{CD} 127^{+}$ & 0.07 & $(0.07-0.07)$ & 0.07 & $(0.06-0.08)$ & 0.7916 \\
\hline NKT cells & $\mathrm{CD}^{+} \mathrm{CD}^{+} \mathrm{CD} 16 / \mathrm{CD}^{2} 6^{+}$ & 0.10 & $(0.10-0.11)$ & 0.09 & $(0.07-0.11)$ & 0.3587 \\
\hline NK cells & $\mathrm{CD}^{-}{ }^{-} \mathrm{CD} 8^{-} \mathrm{CD} 16 / \mathrm{CD}^{-} 6^{+}$ & 0.30 & $(0.29-0.31)$ & 0.29 & $(0.24-0.33)$ & 0.4768 \\
\hline
\end{tabular}

${ }^{*} p$ values from heteroscedastic $t$ tests; ${ }^{\mathrm{a}} \mathrm{TC}+\mathrm{VC} ;{ }^{\mathrm{b}}$ Propensity-score-matched training cohort $(\mathrm{TC}) ;{ }^{\mathrm{c}}$ Validation cohort (VC); ${ }^{\mathrm{d}}$ pack years of smoking history are calculated by multiplying years of self-reported tobacco smoking by the mean of reported cigarettes per day divided by $20 ;{ }^{\text {e }}$ one HA without information on Treg counts.

The following leukocyte subsets were significantly different in numbers per milliliter: granulocytes (SSChigh), neutrophils (SSChigh $\left.\mathrm{CD} 16^{+}\right)$, monocytes $\left(\mathrm{SSC}^{\mathrm{med}} \mathrm{CD} 14^{\text {high }}\right.$ ), classical monocytes (SSC $\left.{ }^{\text {med }} \mathrm{CD} 14^{\text {high }} \mathrm{CD} 16^{\mathrm{dim}}\right)$, total lymphocytes (SSC $\left.{ }^{\text {low }}\right)$, T-lymphocytes $\left(\mathrm{CD} 3^{+} \mathrm{CD} 16^{-} \mathrm{CD} 56^{-}\right)$, and T-cell subpopulations $\left(\mathrm{CD}^{+} \mathrm{CD}^{+}\right.$cytotoxic T-cells, $\mathrm{CD}^{+}{ }^{+} \mathrm{CD} 4^{+} \mathrm{T}$-helper cells, and $\mathrm{CD} 3^{+} \mathrm{CD} 4^{+} \mathrm{CD} 8^{+}$ double-positives). 


\subsection{Calculation of RelCC and PS-Matching}

Since the AbsCC had low power regarding discrimination of HNSCC-CPs and HAs, the RelCCs of nine leukocyte subsets (granulocytes, neutrophils, lymphocytes, T-lymphocytes, T-helper cells, cytotoxic T-cells, monocytes, classical monocytes, and nonclassical monocytes) were calculated and differed significantly (Table 2).

Table 2. The mean and $95 \%$ confidence intervals (CI) for relative cell counts (RelCC) of various leukocyte subsets in peripheral blood based on absolute cell counts (AbsCC) in $10^{9} \cdot \mathrm{L}^{-1}$ detected by 10-color flow cytometry utilizing the OMIP-023 panel [15] in healthy adults (HAs) and HNSCC cancer patients (HNSCC-CPs) in the propensity-score-matched training cohort (TC), the validation cohort (VC), and both combined. Significant differences are shown in bold.

\begin{tabular}{|c|c|c|c|c|c|c|}
\hline \multirow{2}{*}{$\begin{array}{l}\text { Characteristics and } \\
\text { Leukocyte Subsets }\end{array}$} & Unit & \multicolumn{2}{|c|}{$\begin{array}{l}\text { Healthy Adults (HAs) } \\
\text { Mean (95\% CI) }\end{array}$} & \multicolumn{2}{|c|}{$\begin{array}{c}\text { HNSCC Patients } \\
\text { (HNSCC-CPs) } \\
\text { Mean (95\% CI) }\end{array}$} & \multirow[t]{2}{*}{$p$-Value * } \\
\hline & $n$ & \multicolumn{2}{|c|}{963} & \multicolumn{2}{|c|}{101} & \\
\hline Male sex & $\%$ & \multicolumn{2}{|c|}{42.3} & \multicolumn{2}{|c|}{84.2} & $<0.0001$ \\
\hline Age & years & 54.09 & $(52.70-55.48)$ & 60.54 & $(58.54-62.53)$ & $<0.0001$ \\
\hline Tobacco smoking & pack years ${ }^{d}$ & 5.94 & $(4.55-7.32)$ & 32.16 & $(27.25-37.07)$ & $<0.0001$ \\
\hline Alcohol $(\mathrm{g} / \mathrm{d}) 0$ & $\%$ & 14.2 & & 16.0 & & $<0.0001$ \\
\hline$>0-30$ & $\%$ & 72.4 & & 27.0 & & \\
\hline$>30-60$ & $\%$ & 10.2 & & 27.0 & & \\
\hline$>60$ & $\%$ & 3.1 & & 30.0 & & \\
\hline \multicolumn{7}{|l|}{ Cell subsets RelCC } \\
\hline Granulocytes & $\%$ & 64.85 & $(64.16-65.53)$ & 69.24 & $(67.17-71.31)$ & 0.0001 \\
\hline Neutrophils & $\%$ & 60.04 & $(59.33-60.75)$ & 63.42 & $(61.26-65.57)$ & 0.0044 \\
\hline Lymphocytes ${ }^{\mathrm{e}}$ & $\%$ & 30.35 & $(29.67-31.04)$ & 24.11 & $(22.02-26.19)$ & $<0.0001$ \\
\hline T-lymphocytes ${ }^{\mathrm{e}}$ & $\%$ & 21.04 & $(20.49-21.60)$ & 14.91 & $(13.32-16.50)$ & $<0.0001$ \\
\hline Tc cells $\mathrm{e}$ & $\%$ & 4.15 & $(3.96-4.34)$ & 2.31 & $(1.92-2.70)$ & $<0.0001$ \\
\hline Th cells e & $\%$ & 15.23 & $(14.81-15.65)$ & 11.84 & $(10.54-13.14)$ & $<0.0001$ \\
\hline Monocytes ${ }^{f}$ & $\%$ & 4.43 & $(4.32-4.53)$ & 16.43 & (15.46-17.40) & $<0.0001$ \\
\hline nonclassical m. ${ }^{\mathrm{f}}$ & $\%$ & 0.59 & $(0.56-0.61)$ & 0.88 & $(0.76-1.01)$ & $<0.0001$ \\
\hline intermediate $\mathrm{m} . \mathrm{f}$ & $\%$ & 0.09 & $(0.08-0.10)$ & 9.47 & $(8.60-10.33)$ & $<0.0001$ \\
\hline classical m. ${ }^{\mathrm{f}}$ & $\%$ & 3.74 & $(3.65-3.84)$ & 5.89 & $(5.43-6.35)$ & $<0.0001$ \\
\hline PS-matched TC ${ }^{b}$ & $n$ & \multicolumn{2}{|c|}{43} & \multicolumn{2}{|c|}{43} & \\
\hline Male sex & $\%$ & \multicolumn{2}{|c|}{100} & \multicolumn{2}{|c|}{100} & $>0.9999$ \\
\hline Age & years & 60.25 & $(57.15-63.36)$ & 61.78 & $(58.86-64.70)$ & 0.4830 \\
\hline Tobacco smoking & pack years $^{\mathrm{d}}$ & 23.36 & $(15.42-31.30)$ & 26.05 & $(19.60-32.49)$ & 0.6075 \\
\hline Alcohol (g/d) 0 & $\%$ & 16.3 & & 18.6 & & 0.9722 \\
\hline$>0-30$ & $\%$ & 37.2 & & 32.6 & & \\
\hline$>30-60$ & $\%$ & 34.9 & & 37.2 & & \\
\hline$>60$ & $\%$ & 11.6 & & 11.6 & & \\
\hline \multicolumn{7}{|l|}{ Cell subsets RelCC } \\
\hline Granulocytes & $\%$ & 62.82 & $(59.45-66.19)$ & 68.46 & $(65.16-71.76)$ & 0.0215 \\
\hline Neutrophils & $\%$ & 59.86 & $(56.35-63.37)$ & 63.03 & $(59.76-66.31)$ & 0.1983 \\
\hline Lymphocytes & $\%$ & 31.89 & $(28.73-35.06)$ & 24.89 & $(21.48-28.31)$ & 0.0042 \\
\hline T-lymphocytes & $\%$ & 20.67 & $(18.62-22.72)$ & 15.27 & $(12.79-17.74)$ & 0.0015 \\
\hline Tc cells & $\%$ & 3.50 & $(2.97-4.04)$ & 2.53 & $(1.79-3.26)$ & 0.0381 \\
\hline Th cells & $\%$ & 15.68 & $(14.05-17.30)$ & 11.96 & (9.98-13.93) & 0.0056 \\
\hline Monocytes $\mathrm{f}$ & $\%$ & 5.35 & $(4.73-5.97)$ & 16.57 & $(14.88-18.27)$ & $<0.0001$ \\
\hline nonclassical $\mathrm{m} .{ }^{\mathrm{f}}$ & $\%$ & 0.57 & $(0.46-0.68)$ & 0.79 & $(0.62-0.96)$ & 0.0344 \\
\hline intermediate $\mathrm{m} . \mathrm{f}$ & $\%$ & 0.04 & $(0.00-0.08)$ & 9.32 & (7.83-10.81) & $<0.0001$ \\
\hline classical m. ${ }^{\mathrm{f}}$ & $\%$ & 4.74 & $(4.18-5.30)$ & 6.01 & $(5.36-6.66)$ & 0.0048 \\
\hline
\end{tabular}


Table 2. Cont.

\begin{tabular}{|c|c|c|c|c|c|c|}
\hline $\begin{array}{l}\text { Characteristics and } \\
\text { Leukocyte Subsets }\end{array}$ & Unit & \multicolumn{2}{|c|}{$\begin{array}{l}\text { Healthy Adults (HAs) } \\
\text { Mean (95\% CI) }\end{array}$} & \multicolumn{2}{|c|}{$\begin{array}{c}\text { HNSCC Patients } \\
\text { (HNSCC-CPs) } \\
\text { Mean (95\% CI) }\end{array}$} & $p$-Value * \\
\hline $\mathrm{VC}^{\mathrm{c}}$ & $n$ & \multicolumn{2}{|c|}{920} & \multicolumn{2}{|c|}{58} & \\
\hline Male sex & $\%$ & \multicolumn{2}{|c|}{34.3} & \multicolumn{2}{|c|}{72.4} & $<0.0001$ \\
\hline Age & years & 53.23 & $(51.73-54.73)$ & 59.61 & $(56.90-62.32)$ & 0.0001 \\
\hline Tobacco smoking & pack years $^{\mathrm{d}}$ & 3.51 & $(2.69-4.34)$ & 36.70 & (29.79-43.61) & $<0.0001$ \\
\hline Alcohol $(\mathrm{g} / \mathrm{d}) 0^{\circ}$ & $\%$ & 13.9 & & 14.0 & & $<0.0001$ \\
\hline$>0-30$ & $\%$ & 77.3 & & 22.8 & & \\
\hline$>30-60$ & $\%$ & 6.8 & & 19.3 & & \\
\hline$>60$ & $\%$ & 1.9 & & 43.9 & & \\
\hline \multicolumn{7}{|l|}{ Cell subsets RelCC } \\
\hline Granulocytes & $\%$ & 64.94 & $(64.24-65.64)$ & 69.81 & $(67.14-72.48)$ & 0.0010 \\
\hline Neutrophils & $\%$ & 60.04 & $(59.32-60.77)$ & 63.70 & $(60.81-66.59)$ & 0.0199 \\
\hline Lymphocytes ${ }^{\mathrm{e}}$ & $\%$ & 30.28 & (29.58-30.98) & 23.51 & (20.90-26.13) & $<0.0001$ \\
\hline T-lymphocytes e & $\%$ & 21.06 & (20.49-21.63) & 14.64 & $(12.56-16.72)$ & $<0.0001$ \\
\hline Tc cells ${ }^{e}$ & $\%$ & 4.18 & $(3.99-4.37)$ & 2.14 & $(1.73-2.56)$ & $<0.0001$ \\
\hline Th cells ${ }^{e}$ & $\%$ & 15.21 & $(14.77-15.64)$ & 11.75 & $(10.02-13.48)$ & 0.0004 \\
\hline \multirow{4}{*}{$\begin{array}{l}\text { Monocytes } \\
\text { nonclassical m. } \\
\text { intermediate m. } \\
\text { classical } \mathrm{m} .\end{array}$} & $\%$ & 4.38 & $(4.27-4.49)$ & 16.33 & (15.17-17.48) & $<0.0001$ \\
\hline & $\%$ & 0.59 & $(0.56-0.61)$ & 0.95 & $(0.77-1.13)$ & 0.0003 \\
\hline & $\%$ & 0.10 & $(0.09-0.11)$ & 9.58 & $(8.55-10.6)$ & $<0.0001$ \\
\hline & $\%$ & 3.70 & $(3.60-3.80)$ & 5.80 & $(5.16-6.44)$ & $<0.0001$ \\
\hline $\begin{array}{l}* p \text { values from } \mathrm{h} \\
\mathrm{b} \text { Propensity-score- } \\
\text { are calculated by m } \\
\text { divided by } 20 ; \text { e one } \\
\text { on monocyte count. }\end{array}$ & $\begin{array}{l}\text { lastic } t \text { te } \\
\text { trainings } c \\
\text { years of s } \\
\text { P without }\end{array}$ & $\begin{array}{l}\text { C); }{ }^{c} \\
\text { ted to } \\
\text { ion or }\end{array}$ & $\begin{array}{l}\text { ation coho } \\
\text { smoking } \\
\text { hocyte cou }\end{array}$ & $\begin{array}{l}; \mathrm{d} p \\
\text { mean } \\
\text { No HI }\end{array}$ & $\begin{array}{l}\left.\chi^{2}\right) \text { tests; } \\
\text { ears of smo } \\
\text { oorted cigar } \\
\text { CPs withou }\end{array}$ & $\begin{array}{l}\mathrm{C}+\mathrm{VC} ; \\
\text { ig history } \\
\text { es per day } \\
\text { formation }\end{array}$ \\
\hline
\end{tabular}

As shown by Melzer et al. [16], sex and age affect AbsCCs and RelCCs of leukocyte subsets in venous blood. Risk factors linked to development and outcome of HNSCC, including, e.g., high-level intake of alcohol and smoking, might also interfere with AbsCC and RelCC. Of the HAs and HNSCC-CPs, $59.1 \%$ and $15.8 \%$ were nonsmokers; the mean of 5.94 and 32.16 pack years, respectively, also differed significantly (Table 2). Consequently, propensity score (PS)-matching was used to identify a training cohort (TC) of 43 HAs and 43 HNSCC-CPs without significant differences in risk factors (all $p \geq 0.4830$ ). All other HAs and HNSCC-CPs were used as a validation cohort (VC). Besides the characteristics regarding the risk factors sex, age, alcohol, and tobacco smoking, Table 2 shows RelCCs in $\mathrm{TC}, \mathrm{VC}$, and both cohorts combined.

\subsection{Receiver Operating Characteristics and Cut-Offs for Discriminating HAs and HNSCC-CPs}

Whereas mostly classical monocytes were found in HAs, the intermediate monocytes dominated in HNSCC-CPs, and RelCCs of nonclassical monocytes were low in both (Figure 2a). Subsequently, the ratios of all RelCCs were permutated and revealed within the 36 possible ratios the ratios of monocytes-to-granulocytes (MGR), classical monocytes-to-monocytes (clMMR), monocytes-to-lymphocytes (MLR), and monocytes-to-T-lymphocytes (MTLR) as those achieving the highest level of significance (Figure $2 b$ ). 

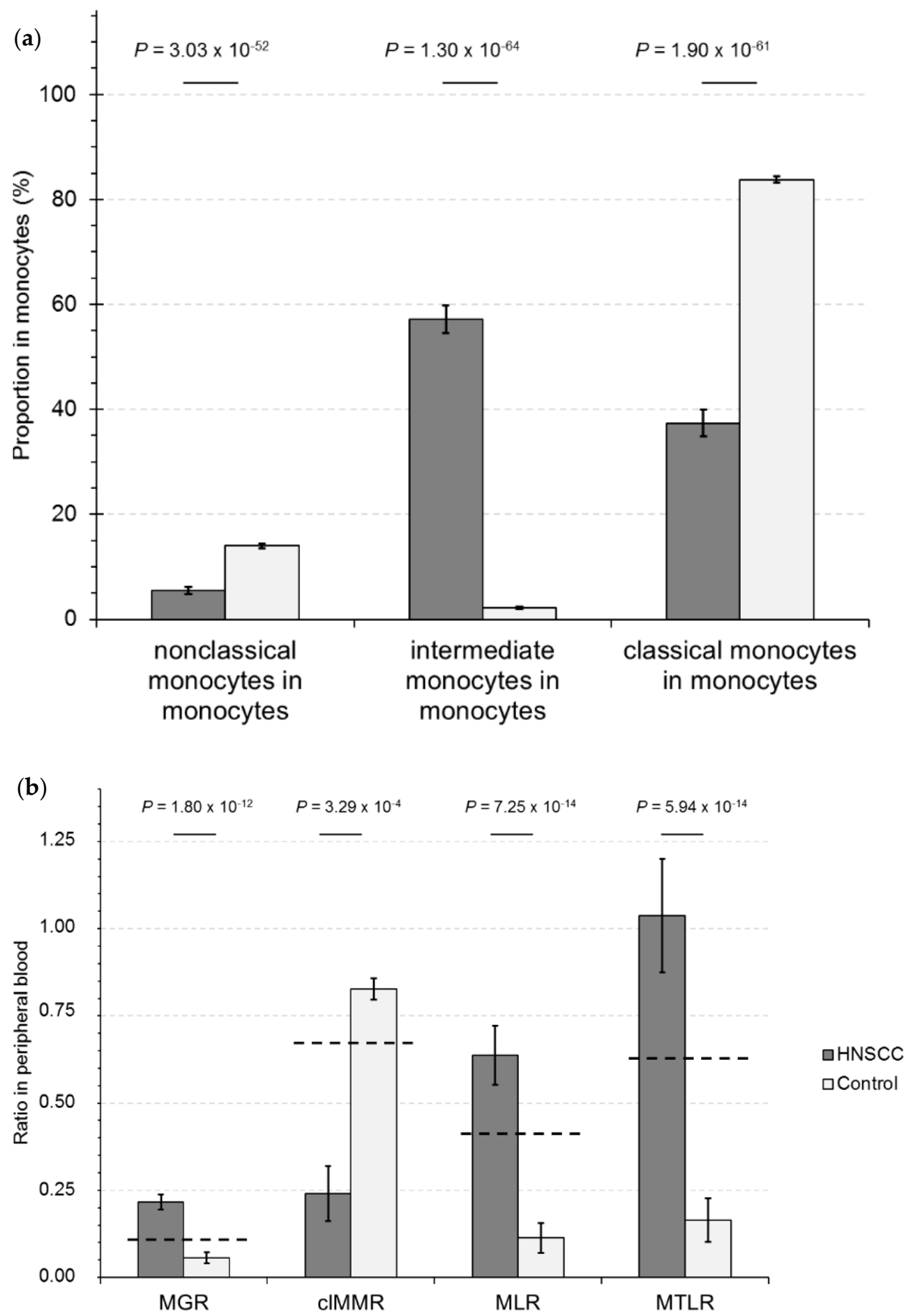

Figure 2. Relative cell counts (RelCCs) of monocyte subsets and ratios of RelCCs of leukocyte subsets defined by 10-color FCM using OMIP-023 [15,16] in peripheral blood (PB) of head and neck squamous cell carcinoma cancer patients (HNSCC-CPs) and healthy adults (control) in the propensity-score-matched (PS-matched) training cohort (TC) of 43 HNSCC-CPs and 43 healthy adults (control). (a) RelCCs shown for nonclassical monocytes in monocytes; intermediate monocytes in monocytes; classical monocytes in monocytes; (b) ratios of RelCCs of granulocytes to monocytes, monocytes to classical monocytes, lymphocytes to monocytes, and T-lymphocytes to monocytes. The corresponding levels of significance in heteroscedastic $t$-tests are shown. 
The percentage of classical $\left(\mathrm{SSC}{ }^{\text {med }} \mathrm{CD} 14^{\text {high }} \mathrm{CD} 16^{\mathrm{dim}}\right.$ ) and nonclassical monocytes (SSC ${ }^{\text {med }} \mathrm{CD} 14^{\mathrm{dim}} \mathrm{CD} 16^{\text {high }}$ ) demonstrated the highest significance and a nearly dichotomous distribution (Figure 2a).

Thereafter, receiver operating characteristic (ROC) curves were used to identify optimum cut-off values for prediction of being an HNSCC-CP. Figure 3 shows the four ratios that achieved the highest level of significance: MGR, clMMR, MLR, and MTLR according to the areas under the curve (AUC) and the corresponding level of significance. These ratios achieved an AUC of 95.6\% (CI 95\% 91.8-99.4\%; $\left.p=6.06 \cdot \times 10^{-13}\right),>99.9 \%\left(\right.$ CI 95\% $\left.100.0-100.0 \% ; p=3.07 \times 10^{-15}\right), 75.7 \%($ CI 95\% 65.1-86.2\%; $\left.p=5.14 \times 10^{-5}\right), 98.4 \%\left(\right.$ CI $\left.95 \% 96.3-100.0 \% ; p=2.37 \times 10^{-14}\right)$ in the TC of 43 HNSCC-CPs and 43 HAs, and $97.4 \%\left(\right.$ CI $\left.95 \% 94.2-100.0 \% ; p=6.69 \cdot \times 10^{-35}\right), 99.8 \%($ CI $95 \% 99.7-100.0 \%$;

mboxemphp $\left.=2.51 \cdot \times 10^{-38}\right), 98.3 \%\left(\right.$ CI 95\% 97.3-99.3\%; $\left.p=1.40 \times 10^{-35}\right)$, and 97.3\% (CI 95\% 96.0-98.7\%; $p=3.18 \times 10^{-34}$ ), respectively, in the validation cohort (VC) of 58 HNSCC-CPs and 920 HAs (Figure 3).

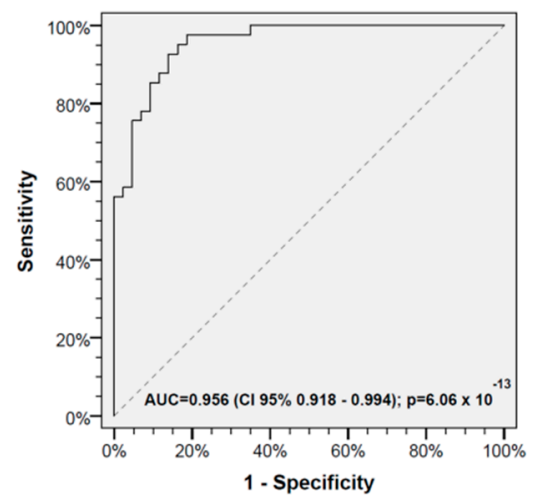

(a)

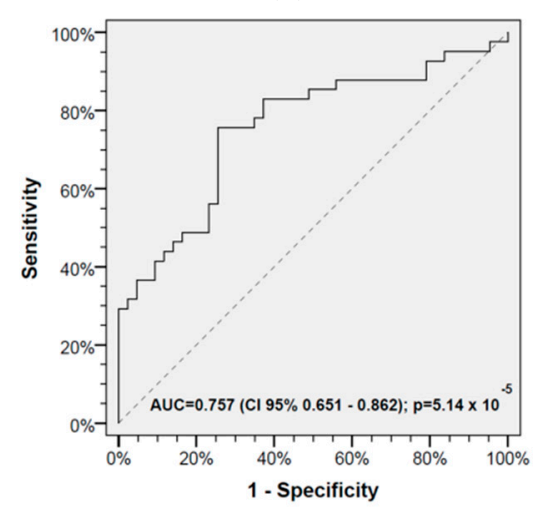

(c)

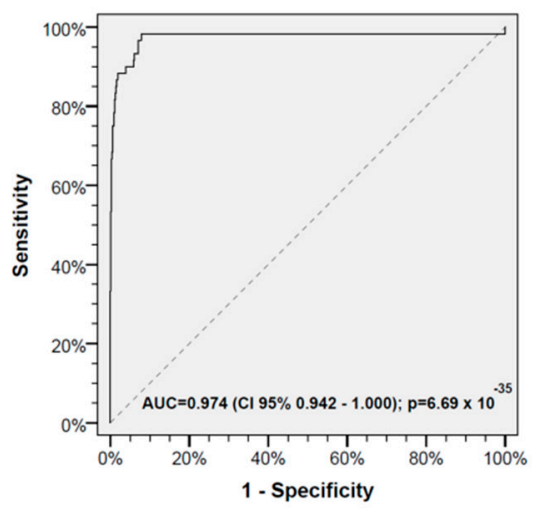

(e)

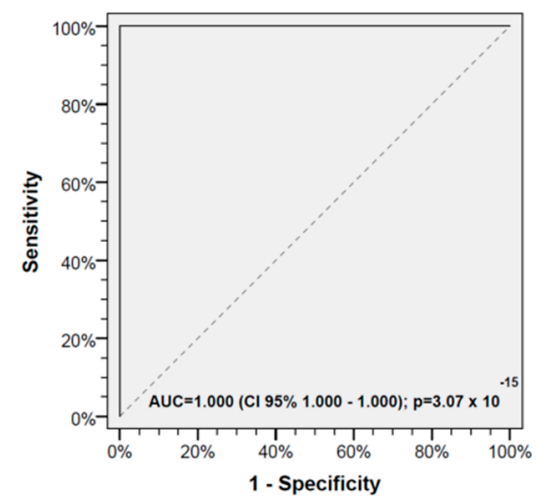

(b)

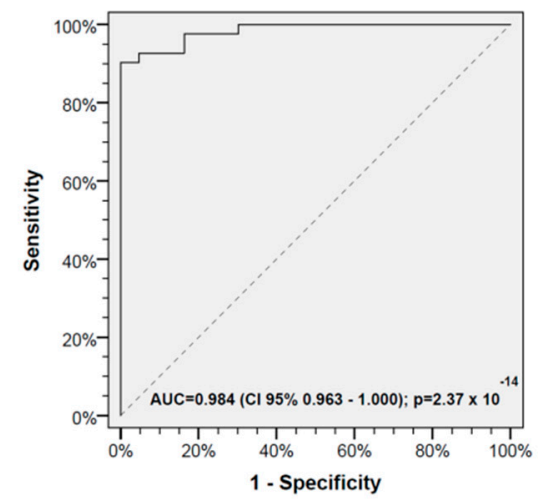

(d)

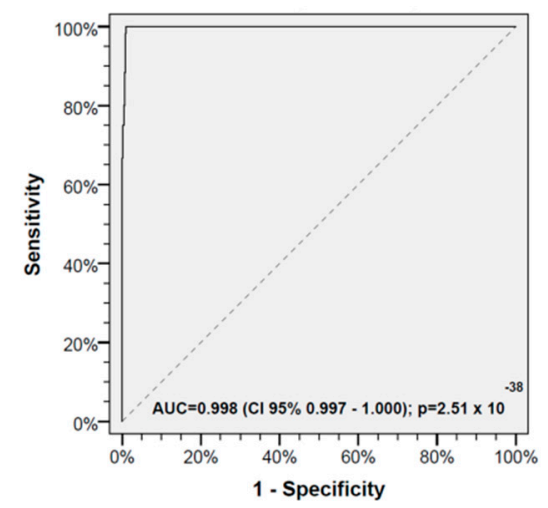

(f)

Figure 3. Cont. 


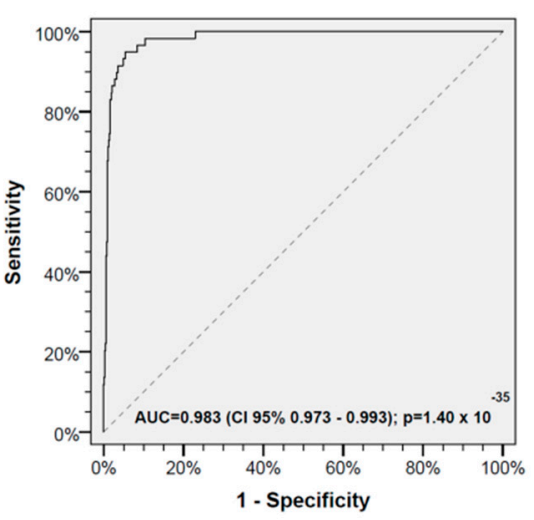

$(\mathrm{g})$

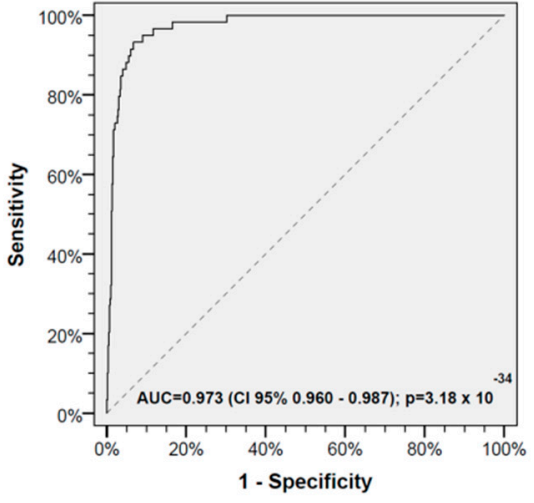

(h)

Figure 3. Receiver operating characteristic (ROC) curves for predicting being a head and neck squamous cell carcinoma cancer patient (HNSCC-CP) by the ratio of relative cell counts (RelCCs). (a,e) Ratio of granulocytes to monocytes; $(\mathbf{b}, \mathbf{f})$ ratio of classical monocytes to monocytes; $(\mathbf{c}, \mathbf{g})$ ratio of lymphocytes to monocytes; $(\mathbf{d}, \mathbf{h})$ ratio of T-lymphocytes to monocytes in $(\mathbf{a}-\mathbf{d})$ the propensity-score-matched (PS-matched) training cohort (TC) of 43 HNSCC-CPs and 43 healthy adults (HAs; left panel), and (e-h) the validation cohort (VC) of 58 HNSCC-CPs and 920 HAs (right panel). Areas under the curve (AUC), the $95 \%$ confidence intervals (CI 95\%), and the corresponding level of significance are shown.

\subsection{Development of a Leukocyte Score to Identify HNSCC-CPS}

The significantly different RelCCs of therapy-naïve HNSCC-CPs as compared to PS-matched HAs allowed for the definition of a score to sum up the number of ratios above the ROC-curve-derived cut-offs. Based on increased RelCCs of monocytes in HNSCC-CPs, the cut-offs for optimum binary classification of HAs are MGR $\leq 0.1110$, MLR $\leq 0.4040$, MTLR $\leq 0.6283$, and clMMR $\geq 0.6733$. Classification of being an HNSCC-CP (that is, MGR, MLR, or MTLR above cut-off and clMMR below cut-off) scored 1. Subsequently, the values achieved for the four scores were summed up, yielding a maximum of four points whenever all ratios pointed to being an HNSCC-CP. A score of $\geq 3$ points was determined as the optimum cut-off for identifying HNSCC-CPs, whereas scores $<3$ defined HAs. The score was then tested on a VC of 920 HAs and 58 HNSCC-CPs. After that, the score was applied to both cohorts combined.

Applying the leukocyte score as new classifier, a sufficient specificity of $>88 \%$ and sensitivity of $>90 \%$ were reached in all three cohorts (Figure 4). In the TC, all HAs and 39 of 43 of the HNSCC-CPs were classified correctly as well as 913 of 920 HAs and 54 of 58 HNSCC-CPs in the VC and 956 of 963 HAs and 93 of 100 HNSCC-CPs in the combined cohort. HNSCC-CPs and HAs could be discriminated in the PS-matched TC $\left(p=2.97 \times 10^{-17}\right)$, the VC $\left(p=4.04 \times 10^{-178}\right)$, and combined $\left(p=7.74 \times 10^{-199}\right)$. Since the number of participants in the HA cohort was much bigger than the number of HNSCC-CPs, the bias- and prevalence-independent measures, the score's Informedness and Markedness were calculated [17] and revealed Informedness and Markedness of $>90 \%$ and $>88 \%$, respectively, in all three cohorts (Figure 4). Bootstrapping utilizing the bias-corrected accelerated (BCa) method revealed significant values for Lambda (0.860, BCa 95\% CI 0.780-0.928; $\left.p<10^{-18}\right)$, Goodman and Kruskal Tau $\left(0.851\right.$, BCa $95 \%$ CI 0.772-0.923; $\left.p=1.19 \times 10^{-198}\right)$, and the uncertainty coefficient $(0.798, \mathrm{BCa} 95 \% \mathrm{CI}$ $\left.0.711-0.885 ; p=3.81 \times 10^{-117}\right)$. Cramer-V $\left(0.923\right.$, BCa 95\% CI 0.879-0.961; $\left.p=7.74 \times 10^{-199}\right)$, Phi $(0.923$, BCa $95 \%$ CI $\left.0.879-0.961 ; p=7.74 \times 10^{-199}\right)$, and the contingency coefficient $C(0.678, \mathrm{BCa} 95 \% \mathrm{CI}$ $0.660-0.693 ; p=7.74 \times 10^{-199}$ ) equally demonstrate a good performance of the score. Cross-validation within the Mantel-Haenszel statistics to estimate conditional probability revealed significance for the combined odds ratio (3254.9, BCa 95\% CI 613.1-17,280.0; $p=2.19 \times 10^{-21}$ ) even on the natural logarithm scale (ln OR = 8.088, BCa 95\% CI 6.797-10.030; $p=1.06 \times 10^{-3}$ ). The a-posteriori (Bayes) probability $P$ (HNSCC-CP|leukocyte score $\geq 3$ ) was found to be $100 \%, 88.5 \%$, and $93.0 \%$ in TC, VC, and in both cohorts combined, respectively. 


\begin{tabular}{|c|c|c|c|c|c|c|c|c|c|c|c|c|c|}
\hline \multirow{2}{*}{ TC } & \multicolumn{2}{|c|}{ HNSCC-CP vs. HA } & \multirow{2}{*}{ Total } & \multirow[b]{3}{*}{ Informedness $90.7 \%$} & \multirow[b]{3}{*}{ Pearson's $x^{2}$} & \multirow[b]{3}{*}{$\begin{array}{r}71.36 \\
p=2.97 \cdot 10^{-17} \\
\end{array}$} & \multirow[b]{3}{*}{$\begin{array}{r}R R_{\text {predicted }} \\
\text { HNscc" (CI } 95 \%)\end{array}$} & \multirow[b]{3}{*}{$79.0(33.5-186.4)$} & \multirow[b]{3}{*}{ Prevalence 50.0\% } & \multirow[b]{3}{*}{ Sensitivity } & \multirow[b]{3}{*}{$90.7 \%$} & \multirow[b]{3}{*}{$\begin{array}{c}\begin{array}{c}\text { Inverse } \\
\text { sensitivity }\end{array} \\
100.0 \%\end{array}$} & \multirow[b]{3}{*}{ Fallout $0.0 \%$} \\
\hline & HNSCC-CP & HA & & & & & & & & & & & \\
\hline predicted HNSCC & 39 & 0 & 39 & & & & & & & & & & \\
\hline predicted $\mathrm{HA}$ & 4 & 43 & 47 & Markedness $91.5 \%$ & $\begin{array}{r}\begin{array}{r}\text { Likelihood } \\
\text { ratio }\end{array} \\
\end{array}$ & $\begin{array}{r}91.86 \\
p=9.30 \cdot 10^{-22}\end{array}$ & OR (Cl 95\%) & -- & Bias $50.0 \% \mathrm{~s}$ & Specificity & $100.0 \%$ & $\begin{array}{c}\begin{array}{c}\text { Inverse } \\
\text { specificity }\end{array} \\
91.5 \% \\
\end{array}$ & Miss rate $\quad 9.3 \%$ \\
\hline Total & 43 & 43 & 86 & $\begin{array}{c}\text { Matthews } \\
\text { correlation } 91.1 \%\end{array}$ & BookMarkG & $83.0 \%$ & $O R^{*}(C 1$ 95\%) & $763.7(207.3-2813.0)$ & \begin{tabular}{|c|}
$\begin{array}{c}\text { Youden- }-90.7 \% \\
\text { index }\end{array}$ \\
\end{tabular} & \begin{tabular}{|c}
$\begin{array}{r}\text { Youden- } \\
\text { score }\end{array}$ \\
\end{tabular} & $190.7 \%$ & $\begin{array}{c}\begin{array}{c}\text { Youden-score } \\
\text { for inverse }\end{array} \\
191.5 \%\end{array}$ & Accuracy $95.3 \%$ \\
\hline \multirow{2}{*}{ vc } & \multicolumn{2}{|c|}{ HNSCC-CP vs. HA } & \multirow{2}{*}{ Total } & & & & & & & & & & \\
\hline & \begin{tabular}{|l|} 
HNSCC-CP \\
\end{tabular} & HA & & & & & & & & & & & \\
\hline predicted HNSCC & 54 & 7 & 61 & Informedness $94.0 \%$ & Pearson's $x^{2}$ & $\begin{array}{r}809.78 \\
p=4.04 \cdot 10^{-178}\end{array}$ & 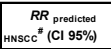 & $115.4(87.6-152.0)$ & Prevalence $5.8 \% \mid \mathrm{S}$ & Sensitivity & $94.7 \%$ & \begin{tabular}{cc|} 
Inverse \\
sensitivity
\end{tabular}$\quad 99.2 \%$ & Fallout $0.8 \%$ \\
\hline predicted HA & 3 & 913 & 916 & Markedness $88.2 \%$ & $\begin{array}{r}\text { Likelihood } \\
\text { ratio }\end{array}$ & $\begin{array}{r}350.74 \\
p=2.92 \cdot 10^{-78}\end{array}$ & OR (Cl 95\%) 2 & $347.7(1501.0-3672.0)$ & Bias $6.2 \% \mathrm{~s}$ & Specificity & $88.5 \%$ & $\begin{array}{cc}\begin{array}{c}\text { Inverse } \\
\text { specificity }\end{array} & 99.7 \% \\
\end{array}$ & Miss rate $\quad 5.3 \%$ \\
\hline Total & 57 & 920 & 977 & 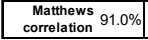 & BookMarkG & $82.9 \%$ & $O R^{z}(C 195 \%)$ & 996.6 (1223.7-2939.4) & \begin{tabular}{|c|}
$\begin{array}{c}\text { Youden- } \\
\text { index } 83.8 \%\end{array}$ \\
\end{tabular} & \begin{tabular}{|c}
$\begin{array}{r}\text { Youden- } \\
\text { score }\end{array}$ \\
\end{tabular} & $183.3 \%$ & $\begin{array}{c}\begin{array}{c}\text { Youden-score } \\
\text { for inverse }\end{array} \\
198.9 \%\end{array}$ & Accuracy $99.0 \%$ \\
\hline \multirow[b]{2}{*}{ Combined } & \multicolumn{2}{|c|}{ HNSCC-CP vs. HA } & \multirow[b]{2}{*}{ tal } & & & & & & & & & & \\
\hline & HNSCC-CP & HA & & & & & & & & & & & \\
\hline predicted HNSCC & 93 & 7 & 100 & Informedness $92.3 \%$ & Pearson's $x^{2}$ & $\begin{array}{r}905.07 \\
p=7.74 \cdot 10^{-199}\end{array}$ & $\begin{array}{r}R R_{\text {predicted }} \\
\text { HNscc }^{*} \text { (Cl 95\%) }\end{array}$ & $119.0(91.6-154.6)$ & Prevalence $9.4 \% \mid \mathrm{s}$ & Sensitivity & $93.0 \%$ & \begin{tabular}{cc|}
$\begin{array}{l}\text { Inverse } \\
\text { sensitivity }\end{array}$ & $99.3 \%$ \\
\end{tabular} & Fallout $\quad 0.7 \%$ \\
\hline predicted HA & 7 & 956 & 963 & Markedness $92.3 \%$ & $\begin{array}{r}\begin{array}{r}\text { Likelihood } \\
\text { ratio }\end{array} \\
\end{array}$ & $\begin{array}{r}529.40 \\
p=3.81 \cdot 10^{-117}\end{array}$ & OR (Cl 95\%) 1 & $314.4(1205.3-2731.4)$ & Bias $9.4 \%$ s & Specificity & $93.0 \%$ & $\begin{array}{cc}\begin{array}{c}\text { Inverse } \\
\text { specificity }\end{array} & 99.3 \% \\
\end{array}$ & Miss rate $\quad 7.0 \%$ \\
\hline Total & 100 & 963 & 1063 & $\begin{array}{c}\text { Matthews } \\
\text { correlation } 92.3 \%\end{array}$ & BookMarkG & $85.1 \%$ & $O R^{z}(C 195 \%)^{1}$ & $889.9(1062.0-2380.3)$ & $\begin{array}{c}\text { Youden- } \\
\text { index } 86.5 \%\end{array}$ & \begin{tabular}{|c}
$\begin{array}{c}\text { Youden- } \\
\text { score }\end{array}$ \\
\end{tabular} & $186.0 \%$ & $\begin{array}{c}\begin{array}{c}\text { Youden-score } \\
\text { for inverse }\end{array} \\
198.5 \%\end{array}$ & Accuracy $98.7 \%$ \\
\hline
\end{tabular}

Figure 4. Binary contingency tables for the training cohort (TC) of 86 propensity-score-matched head and neck squamous cell carcinoma cancer patients (HNSCC-CPs) and healthy adults (HAs), the validation cohort (VC) of 977 cases (57 HNSCC-CPs and 920 HAs), and the combined cohorts (Combined) among 1063 blood samples classified by the leukocyte score. Shade coding indicates correct (gray) vs. incorrect (light gray) decisions with the thereof-derived Bookmaker Informedness [17], Markedness [17], Matthew's correlation (the geometric mean of Bookmaker Informedness and Markedness) [17], relative risk (RR) and 95\% confidence interval (CI 95\%), odds ratio (OR) and CI 95\%, adjusted OR (OR\#) and CI 95\%, Pearson's $\chi^{2}$, likelihood ratio, BookmarkG [17] along with prevalence, bias, Youden index, sensitivity, specificity, Youden-score, inverse sensitivity, inverse specificity, Youden-score for inverse sensitivity and specificity, fall out, miss rate, and accuracy. \# Adjusted according to Cox [18] and Moses et al. [19] by adding 0.5 to each cell to reduce bias and prevent undefined division by zero caused by empty cells.

\subsection{Classification Characteristics of the Leukocyte Score}

Table 3 shows the characteristics of correctly and incorrectly classified HNSCC-CPs. Given the low number of only seven $(7 \%)$ of the 100 blood samples that were not correctly classified as from HNSCC-CP, neither sex, age, localization, Tumor-Node-Metastasis (TNM) category, nor etiologically relevant risk factors, such as smoking history, alcohol consumption, or the HPV status in oropharynx cancer, demonstrated an association with reduced accuracy. Moreover, the leukocyte score demonstrates a potential to also classify blood samples from laryngeal HNSCC-CPs with small-volume disease, including four patients with pTisN0M0 and four with pT1aNOM0, correctly. However, two samples from pT1aN0M0 vocal cord carcinoma and a pT1N0M0 tongue carcinoma patient were among the seven misclassified samples. The only misclassified sample from a T4 cancer was from a male never-smoker of age 88 having a pT4N0M0 hypopharynx cancer, whereas the other misclassified samples were from a young HNSCC-CP without positive neck nodes. There was only one misclassified sample from a HNSCC-CP with multiple neck nodes (from a male heavy drinker with pT3pN2bcM0 tonsillar cancer). 
Table 3. Classification characteristics of the leukocyte score according to various epidemiological and clinical characteristics of HNSCC cancer patients in the combined cohort. No significant differences were detected.

\begin{tabular}{|c|c|c|c|c|c|c|}
\hline \multirow{2}{*}{ Characteristic } & \multirow{2}{*}{ Category } & \multicolumn{2}{|c|}{ Score $\geq 3$} & \multicolumn{2}{|c|}{ Score $<3$} & \multirow{2}{*}{$p$ Value * } \\
\hline & & $\mathbf{n}$ & $(\%)$ & $\mathbf{n}$ & $(\%)$ & \\
\hline \multirow[t]{2}{*}{ Sex } & Female & 14 & $(15.1)$ & 1 & $(14.3)$ & 0.9562 \\
\hline & Male & 79 & $(84.9)$ & 6 & (85.7) & \\
\hline \multirow{4}{*}{ Age (years) } & $<50$ & 12 & (12.9) & 2 & $(28.6)$ & 0.3932 \\
\hline & $50-59$ & 37 & $(39.8)$ & 3 & $(42.9)$ & \\
\hline & $60-69$ & 23 & (24.7) & - & - & \\
\hline & $>70$ & 21 & $(22.6)$ & 2 & (28.6) & \\
\hline \multirow{3}{*}{$\begin{array}{c}\text { Tobacco smoking (pack } \\
\text { years) }\end{array}$} & never smoker & 14 & $(15.1)$ & 2 & $(28.6)$ & 0.5024 \\
\hline & $<30$ & 29 & $(31.2)$ & 1 & (14.3) & \\
\hline & $>30$ & 50 & $(53.8)$ & 4 & (57.1) & \\
\hline \multirow[t]{5}{*}{ Alcohol (g/d) } & 0 & 14 & (15.1) & 1 & (14.3) & 0.8724 \\
\hline & $1-30$ & 24 & $(25.8)$ & 3 & $(42.9)$ & \\
\hline & $31-60$ & 26 & $(28.0)$ & 1 & (14.3) & \\
\hline & $>60$ & 28 & $(30.1)$ & 2 & (28.6) & \\
\hline & Unknown & 1 & $(1.1)$ & - & - & \\
\hline \multirow[t]{2}{*}{ HPV } & p16+ HPV16+ & 16 & $(17.2)$ & - & - & 0.2312 \\
\hline & p16- HPV- & 77 & $(82.8)$ & 7 & $(100.0)$ & \\
\hline \multirow[t]{4}{*}{ Localization } & Oropharynx & 31 & (33.3) & 3 & $(42.9)$ & 0.8241 \\
\hline & Hypopharynx & 10 & (10.8) & 1 & (14.3) & \\
\hline & Larynx & 23 & $(24.7)$ & 2 & $(28.6)$ & \\
\hline & Other & 29 & $(31.2)$ & 1 & (14.3) & \\
\hline \multirow{7}{*}{ UICC stage 7th ed. } & 0 & 4 & $(4.3)$ & - & - & 0.3545 \\
\hline & I & 10 & $(10.8)$ & 2 & (28.6) & \\
\hline & II & 14 & (15.1) & 1 & (14.3) & \\
\hline & III & 7 & (7.5) & 2 & (28.6) & \\
\hline & IVA & 49 & (52.7) & 2 & $(28.6)$ & \\
\hline & IVB & 8 & $(8.6)$ & - & - & \\
\hline & IVC & 1 & (1.1) & - & - & \\
\hline \multirow[t]{3}{*}{ Early vs. advanced } & Advanced & 65 & $(69.9)$ & 4 & $(57.1)$ & 0.5612 \\
\hline & Early & 24 & $(25.8)$ & 3 & $(42.9)$ & \\
\hline & SINIII & 4 & $(4.3)$ & - & - & \\
\hline \multirow[t]{7}{*}{ T category } & Tis & 4 & (4.3) & - & - & 0.8318 \\
\hline & 1 & 18 & (19.4) & 3 & (42.9) & \\
\hline & 2 & 27 & $(29.0)$ & 2 & $(28.6)$ & \\
\hline & 3 & 14 & (15.1) & 1 & (14.3) & \\
\hline & $4 a$ & 24 & $(25.8)$ & 1 & (14.3) & \\
\hline & $4 \mathrm{~b}$ & 3 & (3.2) & - & - & \\
\hline & $x$ & 3 & (3.2) & - & - & \\
\hline \multirow[t]{2}{*}{$\begin{array}{l}\text { T; locally early vs. } \\
\text { advanced }\end{array}$} & T0-T2 & 52 & $(55.9)$ & 5 & $(71.4)$ & 0.4240 \\
\hline & T3-T4 & 41 & $(44.1)$ & 2 & $(28.6)$ & \\
\hline \multirow{6}{*}{$\mathrm{N}$ category } & 0 & 37 & $(39.8)$ & 4 & (57.1) & 0.2369 \\
\hline & 1 & 6 & (6.5) & 2 & (28.6) & \\
\hline & $2 a$ & 1 & (1.1) & - & - & \\
\hline & $2 b$ & 23 & $(24.7)$ & 1 & $(14.3)$ & \\
\hline & $2 c$ & 22 & $(23.7)$ & - & - & \\
\hline & 3 & 4 & (4.3) & - & - & \\
\hline \multirow[t]{2}{*}{ Neck nodes } & No & 37 & $(39.8)$ & 4 & (57.1) & 0.3679 \\
\hline & $\mathrm{N}+$ & 56 & $(60.2)$ & 3 & $(42.9)$ & \\
\hline
\end{tabular}

${ }^{*} p$ values from Pearson's Chi-square $\left(\chi^{2}\right)$ tests.

\section{Discussion}

Within the framework of the LIFE cohort studies (information is provided in 4.1. Subjects), this prospectively defined nested case-control study demonstrates significant differences in AbsCC (Table 1) and RelCC (Table 2) of leukocyte subsets in peripheral blood between HAs and pre-treatment HNSCC-CPs using the validated OMIP-023 antibody cocktail and simultaneous analyses of 15 leukocyte subsets applying 10-color FCM $[15,16]$. Both the AbsCC and the RelCC show significant alterations, especially in the monocytes, classical monocytes, lymphocytes, T-lymphocytes, and granulocytes. Differences between HAs and HNSCC-CPs are mostly discussed as effects of higher age and the 
strongly increased exposure or history of exposure of HNSCC-CP to alcohol and tobacco smoke and the inflammation accompanying these risk factors for HNSCC. Therefore, a PS-matching considering history of tobacco smoking (in pack-years), alcohol consumption (in grams per day), male sex, and age was implemented. A caliper width of 0.2 standard deviations of the linear predictor was used to perform a 1:1 matching as this is an optimal matching algorithm [20] and recommended for PS-matching by Kuss et al. [21].

As the alterations in RelCC are observed despite PS-matching regarding known risk-factors (increased age, male sex, tobacco smoking, and high-level alcohol consumption; Table 2), the differences in AbsCC and RelCC are suggested to be linked rather to the disease than the named risk factors. By permutation of the RelCC of nine leukocyte subsets with significant differences, we were able to discover the four ratios within the 36 combinations demonstrating the highest discriminative power of HAs and HNSCC-CPs based on the individual ratios by using ROC analyses. These four ratios are MGR, MLR, MTLR, and clMMR (Figure 3). They can be combined in a leukocyte score.

The bias- and prevalence-independent measures Markedness [17] of $>88 \%$ and Informedness [17] of $>90 \%$ in TC, VC, and both cohorts combined demonstrate the score's suitability to detect HNSCC-CPs (Figure 4). This is verified by the ability of the score to discriminate HNSCC-CPs from HAs with and without a high risk factor profile. The score detected HNSCC-CPs even in early stages (UICC 0, I, and II) very reliably (28 of the 31 HNSCC-CPs were classified correctly; Table 3). Given the low number of only seven misclassified HNSCC-CPs, we found only insignificant differences with respect to age, sex, localization of the primary lesion, TNM categories and stage, as well as smoking, alcohol consumption, and HPV-driven disease versus others (Table 3).

Suffering from HNSCC is reported to be associated with systemic inflammation marked by an increased number of monocytes and neutrophils in venous blood [22]. Neutrophils of HNSCC-CPs show reduced spontaneous apoptosis compared to HAs; the level of associated cytokines is significantly higher in venous blood of HNSCC-CPs compared to HAs [23]. A lower lymphocyte count and, thus, a higher MLR and NLR correlate with the clinical tumor stage in oropharyngeal squamous cell carcinoma (OPSCC) [24]. T-lymphocytes are suppressed in HNSCC due to, inter alia, an increase of CD14 ${ }^{+}$ HLA-DR ${ }^{-}$myeloid-derived suppressor cells (MDSCs) in peripheral circulation [25]. Lymphopenia in general is an indicator of poor outcome, as lymphocytes play an important role in the anti-tumor immune response [26]. Taken together, numerous studies demonstrated particular ratios, including MLR (or LMR), NLR, and other ratios, to be linked to an altered outcome and even as independent predictors for survival of HNSCC-CPs with primary HNSCC in the larynx, hypopharynx, oropharynx, and the oral cavity $[8,27,28]$. Unsurprisingly, the meta-analyses also found significant prognostic effects of the MLR and other ratios on outcome [28]. However, these ratios observed in HNSCC-CPs were never compared in a sufficient way with those in HAs; in particular, healthy persons with or without identical patterns of the "classical" risk factors for HNSCC. The framework of the LIFE study allowed us to overcome these limitations and demonstrates that the altered ratios are useful not only for prognostic classification of HNSCC-CPs but also as a biomarker for bias-free detection of HNSCC-CPs.

The findings in this study coincide with current studies, as they also show elevated monocytes, classical monocytes, granulocytes, and neutrophils as well as a decrease in lymphocytes and T-lymphocytes in venous blood in HNSCC-CPs in comparison with HAs. The ratios reflect the interaction between the different immune cells and the changes in the immune system over the immune-editing course of HNSCC from elimination and equilibrium to escape $[8,27,28]$.

Our study has limitations. Based on a limited budget and the given time-frame, the HNSCC-CPs of the sub-study LIFE B7 head and neck cancer could not be analyzed completely and 10-color FCM using OMIP-023 was restricted to 161 consecutive patients. Of these, only 101 gave datasets from therapy-naïve primary HNSCC-CPs without synchronous or meta-synchronous diagnosed malignancy of other histology (Figure 1). The pattern of risk factors linked to development of HNSCC required a PS-matching of HAs and HNSCC-CPs to identify the four ratios differing significantly between both and being able to discriminate them in the TC. Combining these potential classifiers allowed for 
building a score. This part of our investigation is, therefore, to be categorized as a hypothesis-generating retrospective analysis. The validation of the score implied the VC that was not independent but rather included the subsample of HNSCC-CPs and HAs not included in the TC. Moreover, one of the 58 HNSCC-CPs was not included in the validation of the score, because the data about the lymphocytes and T-lymphocytes were missing. The two ratios that were known for this patient were higher than the cut-off values and, thus, showed a trend to be classified as an HNSCC-CP. However, no HA control had to be excluded, and, therefore, the comparison of AbsCC, RelCC, and the ratios as well the thereof-derived score is based on a sufficient number of cases. The extension of our analyses to bias- and prevalence-independent measures adds further evidence to the potential benefit of 10-color FCM regarding detection of HNSCC-CPs. Moreover, Bayesian statistics indicated the high a-posteriori probability of being an HNSCC-CP whenever the leukocyte score is $\geq 3$ : $P$ (HNSCC-CP|leukocyte score $\geq 3$ ) in TC, VC, and in both cohorts combined were $100 \%, 88.5 \%$, and $93.0 \%$, respectively. The few misclassified HNSCC-CP cases do not allow for a detailed analysis of misclassification characteristics. However, small-volume disease without local or systemic metastasis is correctly identified, and the risk factors demonstrated no significant effect on the classification characteristics. As our case-control study included only a population-based sample of healthy adults from Leipzig without history or development of HNSCC to date, and we do not have any information about the development of other cancers since providing the blood sample for the here-included analyses, we have to face the well-known limitations of case-control studies.

Unfortunately, no data about the intra-tumoral present leukocyte subsets and their distribution in the HNSCC were available. Further studies should investigate if the here-described differences in peripheral blood can also be observed in the tumor micro-environment and are linked to particular gene expression patterns $[2,14,29,30]$. Also, further research is needed to investigate possible connections between TNM categories, tumor size, and lymph node involvement and leukocyte cell count, MGR, MLR, MTLR, clMMR, and the score. A follow-up study is necessary to investigate the further possible change in leukocyte subsets throughout therapy and after curative treatment.

\section{Materials and Methods}

\subsection{Subjects}

Within the prospective population-based study LIFE, a total of 1064 blood samples were taken after obtaining written informed consent and underwent 10-color FCM analysis (see below). The samples were from two cohorts, 963 participants of LIFE Health Adult recruited at the LIFE study center (age 40 to 79 years, among them 352 with full risk factor anamnesis), and 101 consecutive HNSCC-CPs of the LIFE Head and Neck Cancer cohort [31] accrued between February 2011 and December 2011 (Figure 1). The latter blood samples, from 16 female and 85 male therapy-naïve HNSCC-CPs (age of 30 to 90 years) with pathohistologically confirmed HNSCC without history of malignancy of other histology, were obtained prior to treatment at the ENT Department of the University Hospital Leipzig. Details of the study design of LIFE have been published elsewhere [32]. There were no racial differences as all participants were of Caucasian ethnicity. All HNSCC-CPs and HAs provided written informed consent. Self-reported exposure to the risk factors alcohol and smoking was assessed using standardized questionnaires. The complete protocol of the LIFE study and both sub-studies was approved by the local Ethics Committee of the University Leipzig, Germany (votes 201-10-12072010 and 202-10-12072010).

\subsection{Blood Sample Collection, Preparation, and Staining}

Peripheral blood (PB) was collected in a 9-mL tube (Sarstedt, Germany) containing EDTA as an anticoagulant. Samples were collected in the morning from overnight-fasting participants and were processed within $2 \mathrm{~h}$ after drawing. Sample preparation was performed as described previously $[15,16]$ Briefly, erythrocytes were lysed by adding to $1 \mathrm{~mL}$ of PB $25 \mathrm{~mL}$ of lysis buffer $\left(8.3 \mathrm{~g} \cdot \mathrm{L}^{-1} \mathrm{NH}_{4} \mathrm{Cl}, 1 \mathrm{~g} \cdot \mathrm{L}^{-1}\right.$ 
$\mathrm{KHCO}_{3}$, and $\left.0.04 \mathrm{~g} \cdot \mathrm{L}^{-1} \mathrm{EDTA}\right)$ for $10 \mathrm{~min}$ followed by washing twice with $15 \mathrm{~mL}$ of phosphate-buffered saline (PBS; Sigma-Aldrich, Deisenhofen, Germany) and resuspension in $200 \mu \mathrm{L}$ of PBS supplemented with $5 \mathrm{~g} \cdot \mathrm{L}^{-1}$ bovine serum albumin and $0.5 \mathrm{~g} \cdot \mathrm{L}^{-1}$ sodium azide. Cells were then labeled with an Optimized Multicolor Immunofluorescence Panel (OMIP-023) [15] consisting of 13 antibodies labeled to 10 different fluorochromes $[15,16]$. Optimal antibody concentrations were determined by titration. The monoclonal antibodies were purchased from Beckman Coulter (BC: CA, USA) and Becton Dickinson Labware (BD: NJ, USA). The OMIP-023 consisted of CD3-KrO (T cells; BC B00068), CD4-APC-H7 (Th cells; BD 641398), CD8-FITC (Tc cells; BC A07756), CD14-FITC (LPS co-receptor on monocytes; BC IM0645U), CD45-PB (pan-leukocyte antigen; BC A74743), HLA-DR-APC (MHC-II; BC IM3635), CD69-PE (early-activation antigen; BC IM1943U), CD16-PE-Cy7 (Fc- $\gamma$ receptor III on neutrophils, monocytes, NK; BC 6607118), CD19-FITC (B cells; BC A07768), CD25-ECD (IL2-Receptor, Treg; BC 6607112), CD56-PE-Cy7 (N-Cam on NK, NKT; BC A21692), CD38-PE-Cy5.5 (activated T and B cells; BC A70205), and CD127-APC-Ax700 (IL-7 receptor $\alpha$ chain, Treg; BC A71116). Aliquots of $100 \mu \mathrm{L}$ leukocyte-enriched PB were stained with $2 \mu \mathrm{L}$ of antibodies at room temperature for $2 \mathrm{~h}$ in the dark followed by fixation using $0.5 \%$ paraformaldehyde in PBS and starting the FCM within $4 \mathrm{~h}$.

\subsection{Flow Cytometry (FCM)}

The total white blood cell count (WBC) was determined in all subjects using a Hematology Analyzer XN-9000 (Sysmex Europe GmbH, Norderstedt, Germany). FCM was performed on a Navios flow cytometer (Beckman Coulter, Pasadena, CA, USA), equipped with three lasers (405 nm, $40 \mathrm{~mW}$; $488 \mathrm{~nm}, 22 \mathrm{~mW} ; 638 \mathrm{~nm} ; 25 \mathrm{~mW}$ ) and 10 fluorescence detectors (blue laser: 525/40, 575/30, 620/30, 675/20, 695/30, and 755 LP; red laser: 660/20, 725/20, and 755 LP; and violet laser: 450/50, 550/40 nm). Color compensation values were obtained by single antibody stained cells using the automatic compensation control system of the Navios software. For each OMIP-023, analysis data of $>500,000$ events were collected. Flow cytometric data were analyzed using FlowJo V 7.6.4 (Tree Star, Asland, OR, USA) based on the OMIP-023 gating strategy [15].

\subsection{Quality Control}

The quality controls for the standardization of preanalytics, measurement, and data analysis were detailed elsewhere [15]. In short, for daily measurement, the Navios cytometer was calibrated with microbeads (Rainbow beads; Spherotech, Inc., Libertyville, IL, USA) and lasers were aligned with Flow Check Pro beads (BC). The premixed OMIP-023 antibody cocktail $[15,16]$ was used within 5 days to ensure stability and to minimize pipetting errors. The reliability of manual gating was checked by analyzing identical samples by three evaluators with no significant bias and only low variance between the three readers $\left(R^{2}=0.993\right.$ to 0.999$)$.

\subsection{Manual Gating}

Using the standardized gating protocol published in [15], gating was performed manually for each sample as follows (Figures S1 and S2): exclusion of air bubbles (time versus sideward scatter, SSC log: plot 1), non-single events (forward scatter, FCS time of flight versus FCS lin: plot 2) and CD45 events (anti-CD45 versus SSC log: plot 3). The CD45 ${ }^{+}$events were used to calculate percentages of leukocyte subpopulations. Absolute cell numbers were calculated from these percentages and the WBC count. As WBC counts of 28 HA were not available, AbsCC could be calculated for 935 (TC/VC: 43/892) only and 101 HNSCC-CPs (TC/VC: 43/58). According to SSC height, gates of granulocytes (Figure S2 plot 1A: $\mathrm{CD} 5^{+} \mathrm{SSC}^{\text {high}}$ ), monocytes (plot 1B: $\mathrm{CD} 45^{+} \mathrm{SSC}^{\text {med }}$ ), and lymphocytes (plot 1C: $\mathrm{CD} 45^{+} \mathrm{SSC}^{\text {low }}$ ) were discriminated and further subdivided. Neutrophils (plot 2: $\mathrm{CD} 16^{+}$) and eosinophils (plot 2: $\mathrm{CD} 16^{-}$) in granulocytes were discriminated. After excluding CD14-HLA-DR ${ }^{-}$events (plot 3) and CD4- events (plot 4) from monocyte analysis, classical (typical) monocytes (plot 5: $\mathrm{CD} 14^{++} \mathrm{CD} 16^{+}$) and nonclassical monocytes (plot 5: atypical $\left(\mathrm{CD} 14^{\mathrm{dim}} \mathrm{CD} 16^{++}\right)$plus intermediate $\left(\mathrm{CD} 14^{+} \mathrm{CD} 16^{++}\right)$) were discriminated as well. Lymphocytes (plot 6) were gated into $\mathrm{CD}^{-}$(left; after exclusion of $\mathrm{CD}^{+}$events (plot 7) 
further analyzed in plot 8A: CD16/56 ${ }^{+} \mathrm{NK}$ cells; plot 8B: CD16/56- B-lymphocytes) and CD3 ${ }^{+}$events (right; further analyzed in 9A: $\mathrm{CD}^{+} \mathrm{CD} 16 / 56^{+} \mathrm{NKT}$ cells and 9B: CD3 ${ }^{+} \mathrm{CD} 16 / 56^{-} \mathrm{T}-1 y m p h o c y t e s$ ). Three T-lymphocyte subsets were differentiated (plot 10): CD8 ${ }^{\text {high }}$ cytotoxic T cells (Tc), CD4 ${ }^{+}$T-helper cells (Th), and CD4 ${ }^{+} \mathrm{CD}^{+}$double-positive T-cells (DPT). The gated T-helper cells were also used to identify $\mathrm{CD}_{2} 5^{+}$regulatory T-cells (Treg: anti-CD127 versus anti-CD25, plot 11). Exemplary data of OMIP-023-stained whole blood samples can be found on http://flowrepository.org/ with the Repository ID FR-FCM-ZZ74 and online (Figures S1 and S2).

\subsection{Statistical Considerations and Propensity-Score Matching}

As smoking, alcohol consumption, age, and male sex are prognostic factors for development of HNSCC and, therefore, were expected to be significantly higher in HNSCC-CPs, propensity-score matching (PS-matching) was pre-defined to be used to identify HAs within the total number of adults analyzed in the LIFE-A1 study. A 1:1 PS-matching was performed using SPSS version 24 (IBM, Amonk, NY, USA) with a caliper width of 0.2 standard deviations of the linear predictor $[20,21]$.

\subsection{Statistical Analyses}

Numerical variables were compared between groups using heteroscedastic $t$-tests, whereas categorical variables in contingency tables were compared applying "classical" (biased) statistics to assess Pearson's $\chi^{2}$, likelihood ratio, relative risk (RR) and 95\% confidence interval (CI 95\%), odds ratio (OR) and CI 95\%, adjusted OR (OR\#) and CI 95\%, sensitivity, specificity, Youden index, Youden-score, inverse sensitivity, inverse specificity, Youden-score for inverse sensitivity and specificity, fall out, miss rate, accuracy, prevalence, and bias. We also calculated bias- and prevalence-independent measures BookmarkG [17], Bookmaker Informedness [17], Markedness [17], and Matthew's correlation (the geometric mean of Bookmaker Informedness and Markedness) [17]. Cross-validation was executed using SPSS version 24 (IBM Corporation, Armonk, NY, USA) applying bootstrapping of 1000 iterations and the bias-corrected accelerated (BCa) method to validate the classification characteristics of the leukocyte score. $P$ values below 0.05 were considered significant.

\section{Conclusions}

In-depth immunophenotyping of peripheral blood samples of HAs and therapy-naïve HNSCC-CPs using 10-color flow cytometry identifies the strongest differences in relative cell counts of monocytes, classical monocytes, lymphocytes, and T-lymphocytes. A score based on four leukocyte-subset ratios (clMMR, MLR, MTLR, and MGR) could be developed in a PS-matched TC of 86 (43 HNSCC-CPs vs. 43 HAs) and allows for highly sensitive and specific discrimination of HNSCC-CPs and HAs. The high predictive value of the score could be validated in a validation cohort of 58 HNSCC-CPs versus 920 HAs. This demonstrates the substantially different distribution of particular leukocyte subsets in peripheral blood of HNSCC-CPs. In conclusion, the four leukocyte-subset ratios (clMMR, MLR, MTLR, and MGR) are not only prognostic biomarkers as published earlier but represent biomarkers allowing for the discrimination of HNSCC-CPs and HAs.

Supplementary Materials: The following are available online at http://www.mdpi.com/2072-6694/11/6/814/ s1, Figure S1: Gating strategy for the 10-color 13-antibody panel OMIP-023 using a sample of one subject. EDTA-anticoagulated whole blood was pre-lysed to remove CD45- erythrocytes and to enrich CD45 ${ }^{+}$leukocytes. The stained peripheral blood sample was prepared for analysis by excluding air bubbles (time vs. sideward scatter, plot 1) followed by gating on single-cell events (exclusion of non-single events outside the gate) in plot 2 (time of flight forward scatter vs. forward scatter) before gating in plot 3 (CD45 ${ }^{+}$leukocytes) on the three major subsets, granulocytes (SSC high $)$, monocytes (B, SSC ${ }^{\text {med }}$ ), and lymphocytes $\left(C, S^{\text {low }}\right.$ ) for further analyses (see Figure S2; plot 3 shown here corresponds to plot 1 in Figure S2). Further details can be found in [15] and [16], Figure S2: Gating strategy for the 10-color 13-antibody panel OMIP-023 using a sample of one subject. After exclusion of air bubbles and non-single events (Figure S1), CD45 ${ }^{+}$cells (leukocytes) were gated according to SSC height to analyze granulocytes SSC high (plot 2), monocytes (SSC ${ }^{\text {med; }}$; plots 3 to 5), and lymphocytes (SSC ${ }^{\text {low }}$; plots 6 to 11). Further details can be found in the Methods section* and in [15] and [16]. 
Author Contributions: Conceptualization, G.W., M.L., and A.T.; Data curation, G.W., C.G., S.M., J.B., S.H., C.E., K.W., J.R.W., T.W., J.F., M.W., M.K., S.W., and A.T.; Formal analysis, G.W., C.G., S.M., J.B., S.H., and A.T.; Funding acquisition, G.W., C.E., M.L., A.D., and A.T.; Investigation, G.W., C.G., S.M., J.B., and A.T.; Methodology, G.W., S.M., J.B., and A.T.; Project administration, G.W., S.M., C.E., K.W., M.L., A.D., and A.T.; Resources, G.W., M.L., A.D., and A.T.; Supervision, G.W., S.M., J.B., M.L., A.D., and A.T.; Validation, G.W., C.G., S.M., J.B., M.K., and A.T.; Visualization, G.W., C.G., S.M., and J.B.; Writing-original draft, G.W. and C.G.; Writing-review \& editing, G.W., C.G., S.M., J.B., S.H., C.E., K.W., J.R.W., T.W., J.F., M.W., M.K., S.W., M.L., A.D., and A.T.

Funding: The study was supported by the grants LIFE-006 A1, LIFE-006 B7, LIFE-006 C2, and LIFE-007 D9 of the Leipzig Research Center for Civilization Diseases (LIFE), University Leipzig. LIFE is funded by the European Union, the European Fund for Regional Development (EFRE), and the Free State of Saxony. The funding sources did not influence the design of the study, the collection, interpretation, and analysis of the data, the preparation of this report, or the decision to publish.

Acknowledgments: We thank all participants of the population-based study LIFE and the HNSCC patients participating in the investigation and their families. We thank all physicians and laboratory staff in the involved departments, especially Anett Reiche, Birgit Ronneberger, and Aniko Szabo for excellent technical assistance as well as Pia Rethfeld, Melanie Gross, and Marlene Kautzner for supporting the leukocyte subset analyses. We are thankful for the quick review and the very helpful comments and suggestions from the four reviewers to add additional information about classification characteristics for particular HNSCC patient groups.

Conflicts of Interest: The authors declare no conflicts of interest. The funders had no role in the design of the study; in the collection, analyses, or interpretation of data; in the writing of the manuscript, or in the decision to publish the results.

\section{References}

1. Union for International Cancer Control (UICC). Review of Cancer Medicines on the WHO List of Essential Medicines—Head and Neck; UICC: Geneva, Switzerland, 2014; pp. 1-8.

2. Leemans, C.R.; Braakhuis, B.J.M.; Brakenhoff, R.H. The molecular biology of head and neck cancer. Nat. Rev. Cancer 2011, 1, 9-22. [CrossRef] [PubMed]

3. Wichmann, G.; Herchenhahn, C.; Boehm, A.; Mozet, C.; Hofer, M.; Fischer, M.; Kolb, M.; Dietz, A. HLA traits linked to development of head and neck squamous cell carcinoma affect the progression-free survival of patients. Oral Oncol. 2017, 69, 115-127. [CrossRef] [PubMed]

4. Wichmann, G.; Lehmann, C.; Herchenhahn, C.; Kolb, M.; Hofer, M.; Wiegand, S.; Dietz, A. Development of a Human Leukocyte Antigen Score to Predict Progression-Free Survival in Head and Neck Squamous Cell Carcinoma Patients. Front. Oncol. 2018, 8, 168. [CrossRef] [PubMed]

5. Schneiders, F.L.; de Bruin, R.C.G.; van den Eertwegh, A.J.M.; Scheper, R.J.; Leemans, C.R.; Brakenhoff, R.H.; Langendijk, J.A.; Verheul, H.M.W.; de Gruijl, T.D.; Molling, J.W.; et al. Circulating invariant natural killer T-cell numbers predict outcome in head and neck squamous cell carcinoma: Updated analysis with 10-year follow-up. J. Clin. Oncol. 2012, 5, 567-570. [CrossRef] [PubMed]

6. Bergmann, C.; Strauss, L.; Wang, Y.; Szczepanski, M.J.; Lang, S.; Johnson, J.T.; Whiteside, T.L. T regulatory type 1 cells in squamous cell carcinoma of the head and neck: Mechanisms of suppression and expansion in advanced disease. Clin. Cancer Res. 2008, 14, 3706-3715. [CrossRef]

7. Schaefer, C.; Kim, G.G.; Albers, A.; Hoermann, K.; Myers, E.N.; Whiteside, T.L. Characteristics of CD4+CD25+ regulatory T cells in the peripheral circulation of patients with head and neck cancer. Br. J. Cancer 2005, 92, 913-920. [CrossRef]

8. Zeidler, R.; Csanady, M.; Gires, O.; Lang, S.; Schmitt, B.; Wollenberg, B. Tumor cell-derived prostaglandin E2 inhibits monocyte function by interfering with CCR5 and Mac-1. FASEB J. 2000, 14, 661-668. [CrossRef]

9. Dumitru, C.A.; Lang, S.; Brandau, S. Modulation of neutrophil granulocytes in the tumor microenvironment: Mechanisms and consequences for tumor progression. Semin. Cancer Biol. 2013, 23, 141-148. [CrossRef]

10. Sumner, W.A.; Stokes, W.A.; Oweida, A.; Berggren, K.L.; McDermott, J.D.; Raben, D.; Abbott, D.; Jones, B.; Gan, G.; Karam, S.D. Survival impact of pre-treatment neutrophils on oropharyngeal and laryngeal cancer patients undergoing definitive radiotherapy. J. Trans. Med. 2017, 15, 168. [CrossRef]

11. Krieg, C.; Nowicka, M.; Guglietta, S.; Schindler, S.; Hartmann, F.J.; Weber, L.M.; Dummer, R.; Robinson, M.D.; Levesque, M.P.; Becher, B. High-dimensional single-cell analysis predicts response to anti-PD-1 immunotherapy. Nat. Med. 2018, 24, 144-153. [CrossRef] 
12. Tham, T.; Olson, C.; Khaymovich, J.; Herman, S.W.; Costantino, P.D. The lymphocyte-to-monocyte ratio as a prognostic indicator in head and neck cancer: A systematic review and meta-analysis. Eur. Arch. Otorhinolaryngol. 2018, 275, 1663-1670. [CrossRef] [PubMed]

13. Kano, S.; Homma, A.; Hatakeyama, H.; Mizumachi, T.; Sakashita, T.; Kakizaki, T.; Fukuda, S. Pretreatment lymphocyte-to-monocyte ratio as an independent prognostic factor for head and neck cancer. Head Neck 2017, 39, 247-253. [CrossRef] [PubMed]

14. Templeton, A.J.; McNamara, M.G.; Šeruga, B.; Vera-Badillo, F.E.; Aneja, P.; Ocaña, A.; Leibowitz-Amit, R.; Sonpavde, G.; Knox, J.J.; Tran, B.; et al. Prognostic role of neutrophil-to-lymphocyte ratio in solid tumors: A systematic review and meta-analysis. J. Natl. Cancer Inst. 2014, 106. [CrossRef] [PubMed]

15. Bocsi, J.; Melzer, S.; Dähnert, I.; Tárnok, A. OMIP-023: 10-color, 13 antibody panel for in-depth phenotyping of human peripheral blood leukocytes. Cytom. Part A 2014, 85, 781-784. [CrossRef] [PubMed]

16. Melzer, S.; Zachariae, S.; Bocsi, J.; Engel, C.; Löffler, M.; Tárnok, A. Reference intervals for leukocyte subsets in adults: Results from a population-based study using 10-color flow cytometry. Cytom. Part B Clin. Cytom. 2015, 88, 270-281. [CrossRef] [PubMed]

17. Powers, D. Evaluation: From precision, recall and F-measure to ROC, informedness, markedness and correlation. JMLT 2011, 2, 37-63.

18. Cox, D.R. The Analysis of Binary Data, 1st ed.; Methuen: London, UK, 1970; p. 142. ISBN 0416104002.

19. Moses, L.E.; Shapiro, D.; Littenberg, B. Combining independent studies of a diagnostic test into a summary ROC curve: Data-analytic approaches and some additional considerations. Stat. Med. 1993, 12, 1293-1316. [CrossRef]

20. Austin, P.C. Optimal caliper widths for propensity-score matching when estimating differences in means and differences in proportions in observational studies. Pharm. Stat. 2011, 10, 150-161. [CrossRef]

21. Kuss, O.; Blettner, M.; Börgermann, J. Propensity Score: An Alternative Method of Analyzing Treatment Effects: Part 23 of a Series on Evaluation of Scientific Publications. Dtsch. Ärztebl. Int. 2016, 113, 597-603. [CrossRef]

22. Millrud, C.R.; Månsson Kvarnhammar, A.; Uddman, R.; Björnsson, S.; Riesbeck, K.; Cardell, L.O. The activation pattern of blood leukocytes in head and neck squamous cell carcinoma is correlated to survival. PLoS ONE 2012, 7, e51120. [CrossRef]

23. Trellakis, S.; Farjah, H.; Bruderek, K.; Dumitru, C.A.; Hoffmann, T.K.; Lang, S.; Brandau, S. Peripheral blood neutrophil granulocytes from patients with head and neck squamous cell carcinoma functionally differ from their counterparts in healthy donors. Int. J. Immunopathol. Pharmacol. 2011, 24, 683-693. [CrossRef] [PubMed]

24. Kågedal, Å.; Rydberg Millrud, C.; Häyry, V.; Kumlien Georén, S.; Lidegran, M.; Munck-Wikland, E.; Cardell, L.-O. Oropharyngeal squamous cell carcinoma induces an innate systemic inflammation, affected by the size of the tumour and the lymph node spread. Clin. Otolaryngol. 2018, 43, 1117-1121. [CrossRef]

25. Chikamatsu, K.; Sakakura, K.; Toyoda, M.; Takahashi, K.; Yamamoto, T.; Masuyama, K. Immunosuppressive activity of CD14+ HLA-DR- cells in squamous cell carcinoma of the head and neck. Cancer Sci. 2012, 103, 976-983. [CrossRef] [PubMed]

26. Ray-Coquard, I.; Cropet, C.; van Glabbeke, M.; Sebban, C.; Le Cesne, A.; Judson, I.; Tredan, O.; Verweij, J.; Biron, P.; Labidi, I.; et al. Lymphopenia as a prognistic factor for overall survival in advanced carcinomas, sarcomas and lymphomas. Cancer Res. 2009, 69, 5383-5391. [CrossRef] [PubMed]

27. Wu, D.Q.; Huang, X.S. The significance of lymphocyte to monocyte ratio in peripheral blood of patients with benign and malignant laryngeal lesions. Lin Chuang Er Bi Yan Hou Tou Jing Wai Ke Za Zhi 2017, 31, 835-838. [CrossRef] [PubMed]

28. Yang, J.; Hsueh, C.-Y.; Cao, W.; Zhou, L. Pretreatment lymphocyte-to-monocyte ratio as an independent prognostic factor for hypopharyngeal squamous cell carcinoma. Acta Otolaryngol. 2018, 138, 734-740. [CrossRef] [PubMed]

29. Keck, M.K.; Zuo, Z.; Khattri, A.; Stricker, T.P.; Brown, C.D.; Imanguli, M.; Rieke, D.; Endhardt, K.; Fang, P.; Brägelmann, J.; et al. Integrative analysis of head and neck cancer identifies two biologically distinct HPV and three non-HPV subtypes. Clin. Cancer Res. 2015, 21, 870-881. [CrossRef] [PubMed]

30. The Cancer Genome Atlas Network. Comprehensive genomic characterization of head and neck squamous cell carcinomas. Nature 2015, 517, 576-582. [CrossRef] [PubMed] 
31. Wichmann, G.; Rosolowski, M.; Krohn, K.; Kreuz, M.; Boehm, A.; Reiche, A.; Scharrer, U.; Halama, D.; Bertolini, J.; Bauer, U.; et al. The role of HPV RNA transcription, immune response-related gene expression and disruptive TP53 mutations in diagnostic and prognostic profiling of head and neck cancer. Int. J. Cancer 2015, 137, 2846-2857. [CrossRef] [PubMed]

32. Loeffler, M.; Engel, C.; Ahnert, P.; Alfermann, D.; Arelin, K.; Baber, R.; Beutner, F.; Binder, H.; Brahler, E.; Burkhardt, R.; et al. The LIFE-Adult-Study: Objectives and design of a population-based cohort study with 10,000 deeply phenotyped adults in Germany. BMC Public Health 2015, 15, 691. [CrossRef] [PubMed]

(C) 2019 by the authors. Licensee MDPI, Basel, Switzerland. This article is an open access article distributed under the terms and conditions of the Creative Commons Attribution (CC BY) license (http://creativecommons.org/licenses/by/4.0/). 